القدرات العسكرية للمملكة العربية السعودية

\author{
ميثاق خيرالهه جلود \\ مدرس مساعد/ قسم الدراسات السياسية والإستراتيجية /مركز الدراسات الإقليمية
}

مستخلص البحث

استطاعت المملكـة العربيـة السـودية تجـاوز عقبـات مهــة وأفـادت من علاقاتها

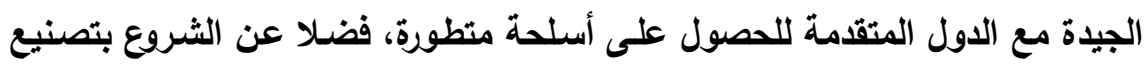

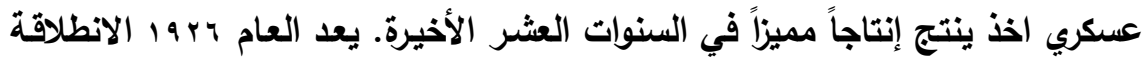

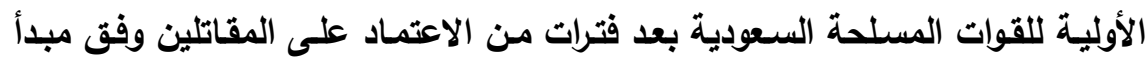

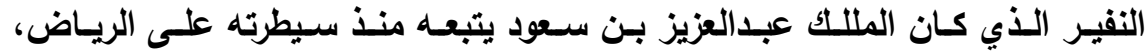

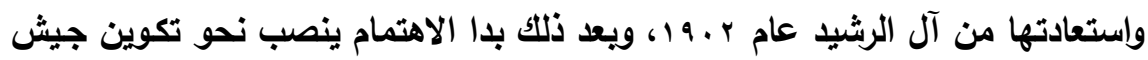

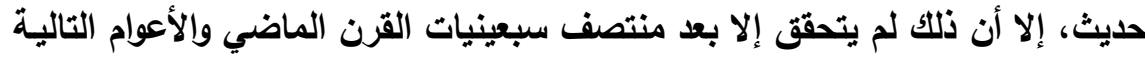

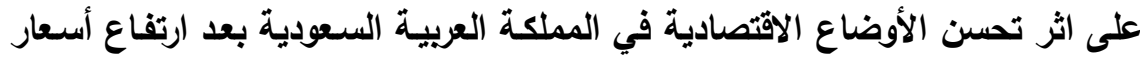

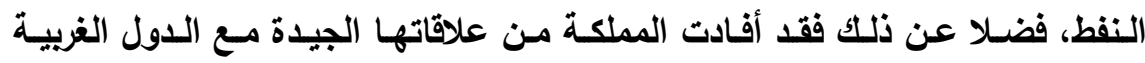

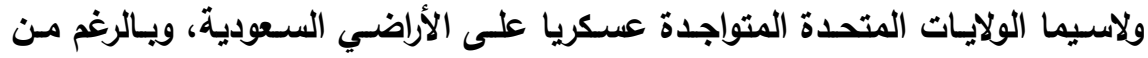

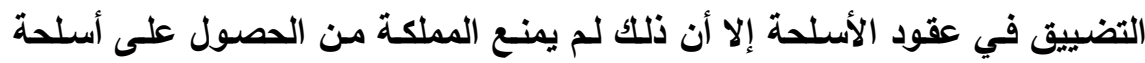
حديثة، ويخاصـة الطـائرات المقاتلـة مـن طراز (F-15) وطائرة (التورنـادو) البريطانيـة

تمثل القوة العسكرية معياراً أساسياً لقياس مدى قوة وتطور الدول، كما إنها تعد ضمانة لسـامة الحدود، وسبباً في الردع حتى قبل الثروع في استخدام السـلاح، وهذا السبب هو الذي يدفع بعض الدول الى بـل جهود مضنية وندية وأموال طائلة لتحديث جيوشها والحصول على احدث الأسلحة، ومحاولة بناء 
تصنيع أو صناعة عسكرية، وضمن هذا السياق فان عددا من الدول العربية تحاول الأخذ بأسباب القوة كالمملكة العربية السعودية ومصر وسوريا، إلا أنها

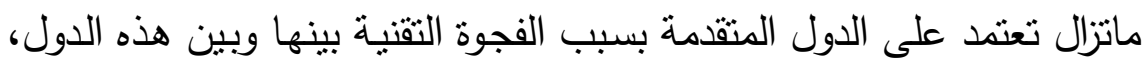

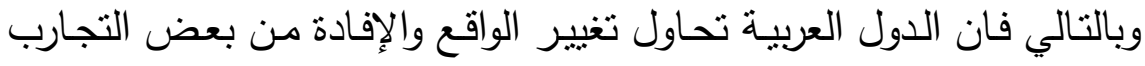

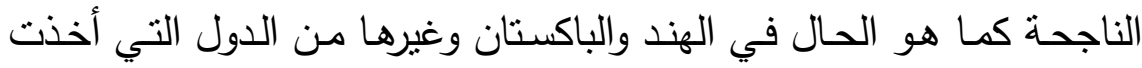

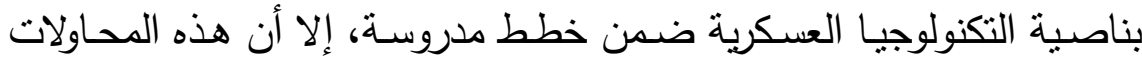
مازالت تفتقر الى التخطيط السليم.

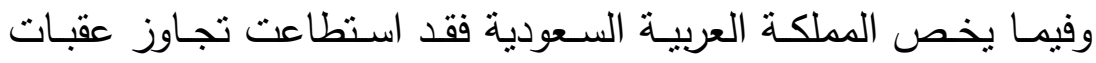

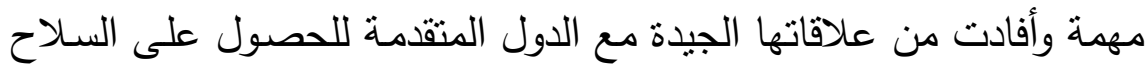

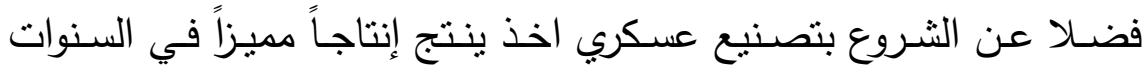
العشر الأخيرة، ووفق هذا المنطلق نم نسليط الضوء على التى القدرات العسكرية

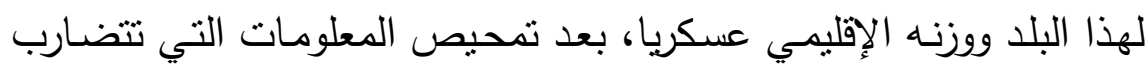

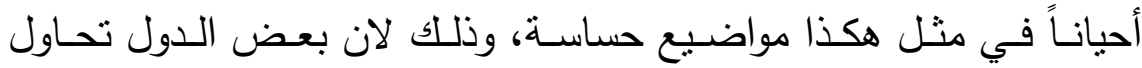
تضخيم قدراتها العسكرية، وأخرى تحاول إخفاء بعض المانية المعلومات العسكرية المهمة. وقد تم تتاول المواضيع من خلال المحاور التالية:

1- نشأة وتطور القوات المسلحة السعودية. r- الإمكانات القتالية للقوات المسلحة السعودية. r- باقع التصنيع العسكري في المملكة العربية السعودية. ع - التعاون العسكري للمملكة العربية السعودية مع الدولية العرلة الأجنبية. ه- مستقبل القدرات العسكرية للمملكة العربية السعودية.

1- نثأة وتطور القوات المسلحة السعودية

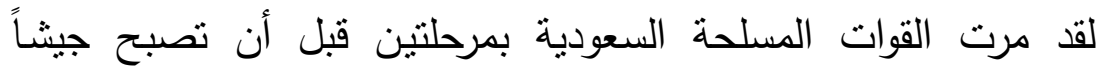

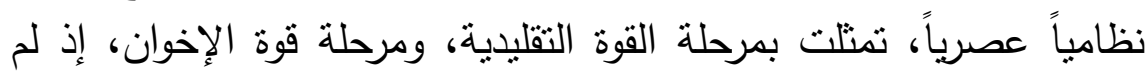


يكن للملك عبد العزيز بن سعود (r.9.190ـ19) جيشاً نظامياً خلال حروب توحيد المملكة وتثبيت حكمه على كافة أجزائها، فكان اعتماده على جيش

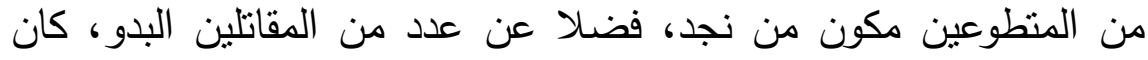

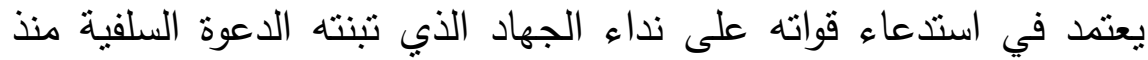

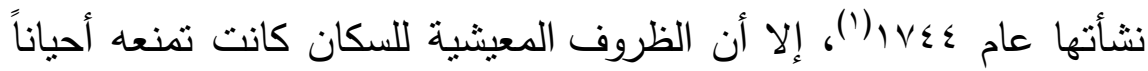
كثيرة من الاحتقاظ بالمقاتلين فترات طويلة. لذا قام بإيجاد قوة يعتمد عليها

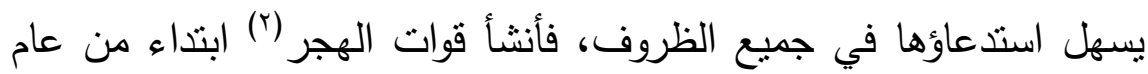

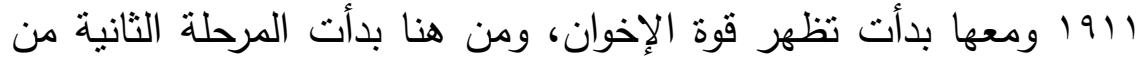

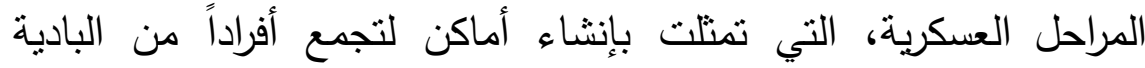
ليستقروا ويتركوا حياة الترحال، وأن أول هجرة تأسست عام

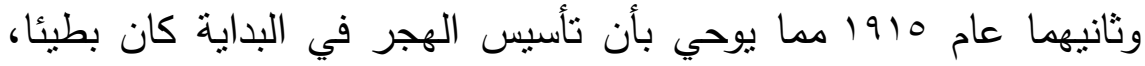

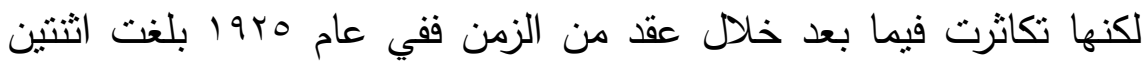

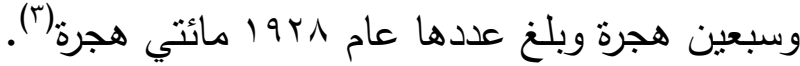
ومنذ توحيد المملكة تحت مسمى مملكة نجد والحجاز وملحقاتها (قبل أن

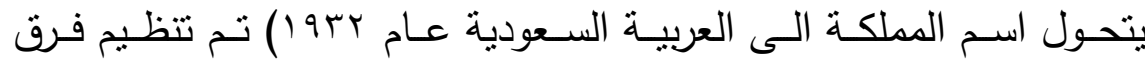

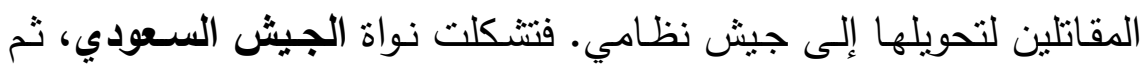

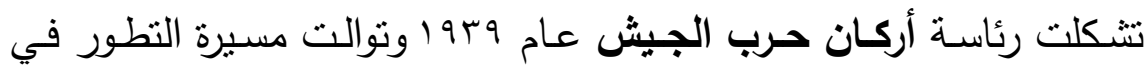
القوات المسلحة السعودية، التي كان بمثل عمودها الفقري الجيش العربي التئي

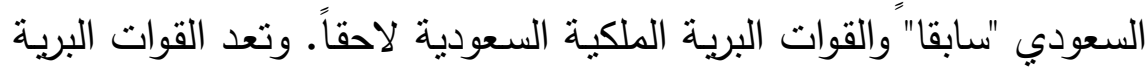
السـودية أقدم تشكيلات الجيش السـعودي وقد جـاء تطور البنيـة القتاليـة للقوات البريـة، من خـلا تطور قيادات أسلحتها الرئيسـة وكان أول نشكيل ونيل

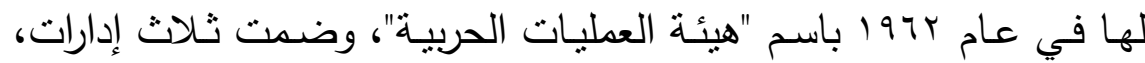
هي: إدارة التنظيم والتسليح، والتدريب الحربي، والخطط والعمليات. وهي من بن التهابـ أقدم الهيئات في الجيش السعودي، وتسمى "إدارة الجيش". وكانت تضم في ولي ولئ 
بدايتها، هيئات وإدارات الجيش المختلفة. وفي عام $19 V Y$ أعيد تتظيم هيئة

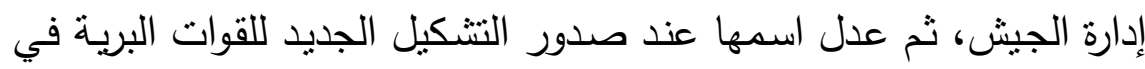

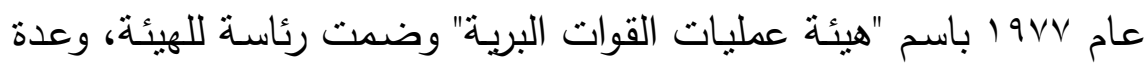

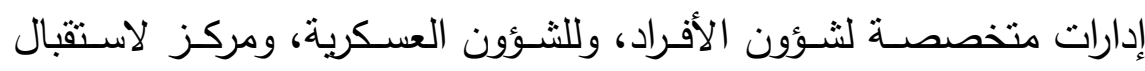
وتجنيد المستجدين في الرياض، وإدارة لشؤون موظفي القوات البرية والمعهد

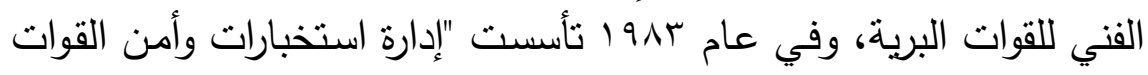

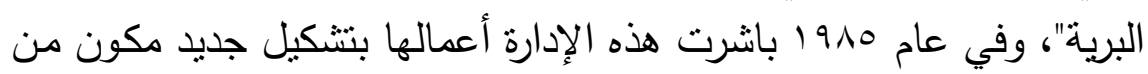

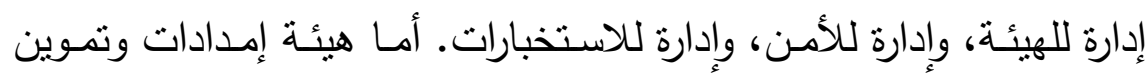
القوات البرية فقد كانت تسمى "هيئة إمدادات الجيش"، وعندما تم تتظيم قيادة ودات

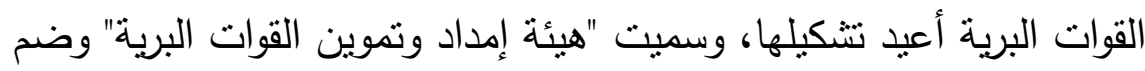
تتكيلها إدارات مختلفة، كما ربطت بها قواعد الإمدادات والتموين (؛). وفيما يخص القوة الجوبة السعودية فإن الملك عبدالعزيز أبدى اهتمامه إلها

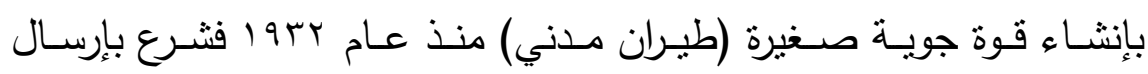

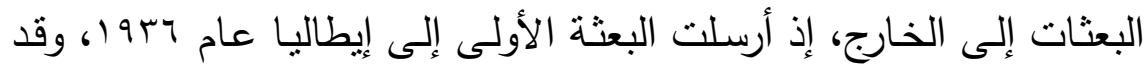

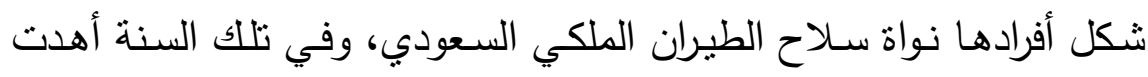

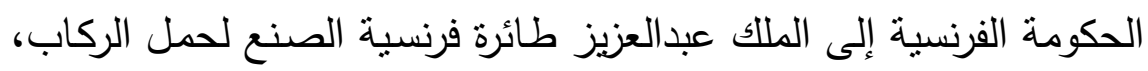

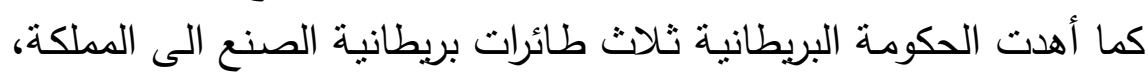
كما تعاقدت السعودية معها على إنشاء مطار عباس بن فرناس (جدة) إذ تم

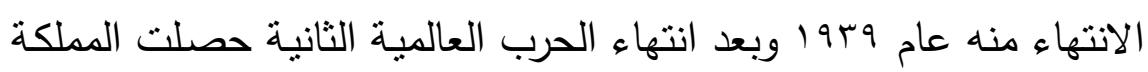

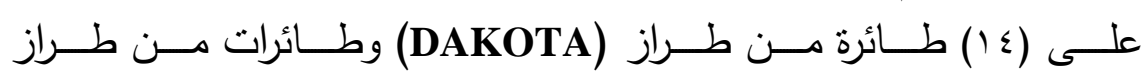

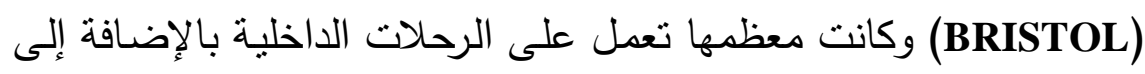

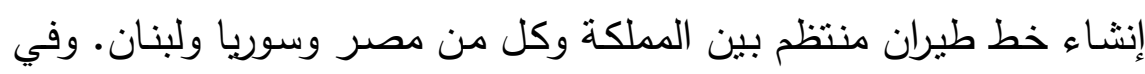

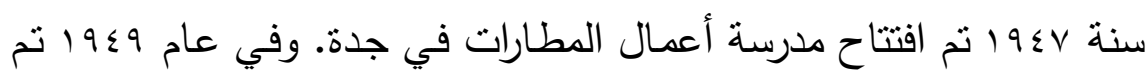

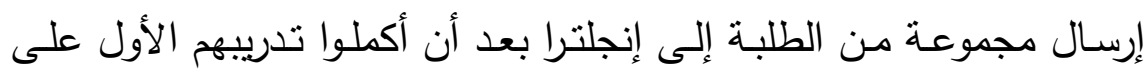

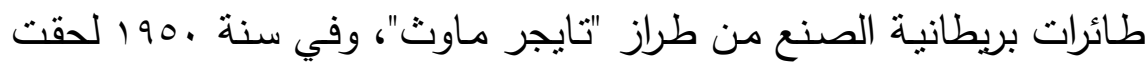


بهم دفعـة أخرى، وتبعهم بعد ذلك مجموعـة ثالثة إلى الولايـات المتحدة

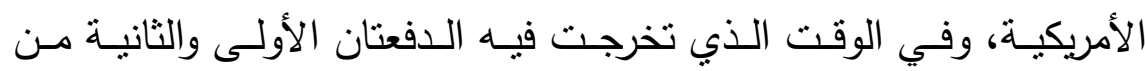
بريطانيا عام 1901 تم تشكيل القوات الجوية بصورة رسمية، وكانت تابعة لمكتب شؤون الطيران بوزارة الدفاع، ورفع أول علم لسلاح الطيران السعودي بـوني

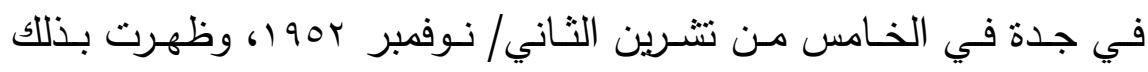

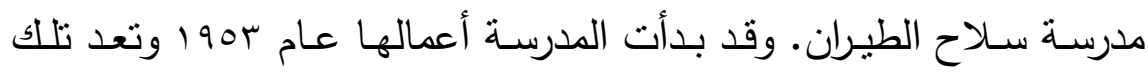

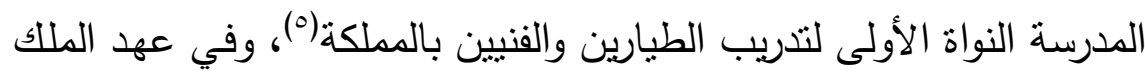
سعود بن عبدالعزبز (904 (19 194) تم الحصول على عدد من الطائرات المقاتلـة، وطائرات النقل التي شملت طـائرات (CHIPMUNK) وطائرات

(TEXANT-6)

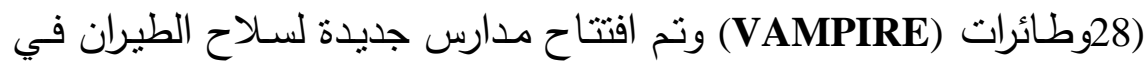
جدة، ثم نقلت إلى الظهران تحت اسم (وحدة تدريب القتال) وفي عهد الملك

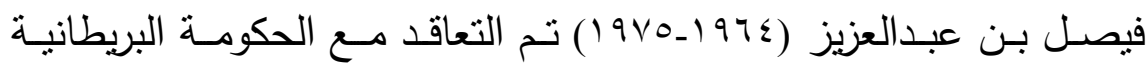

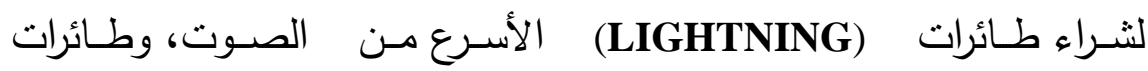

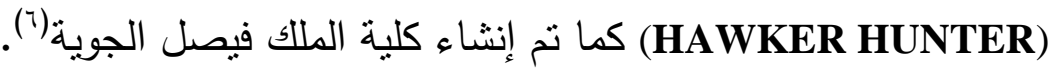
أما القوة البحرية فإنها تعد الأحدث تكوينا بين صنوف القوات المسلحة

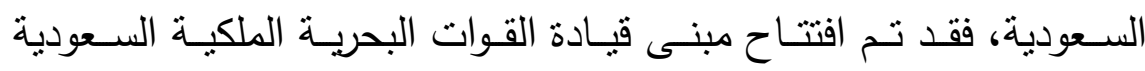
بالرياض عام •و191 ومن ثم استلام وتشغيل المرحلة الثانية من مبنى قيادة

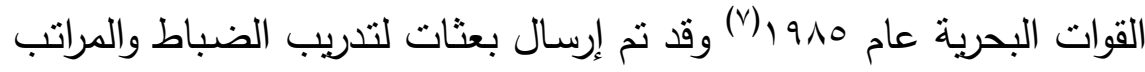
الى مصر وباكستان والولايات المتحدة الأمريكية وفرنسا، ثم تولت الت القوات التوات

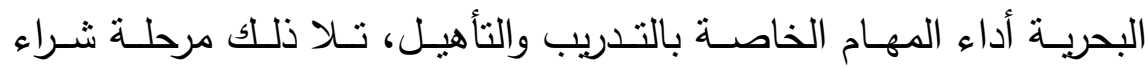
الأسلحة والمعدات، إذ تم شراء معدات وزوارق حربية من الماتيـا، كما تم

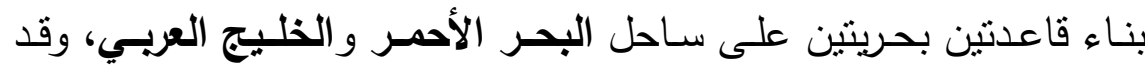

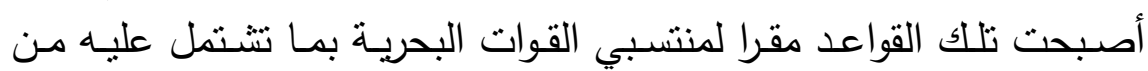


مرافق وخدمات، ومراكز أبحاث، ومدارس عسكرية ومدنيـة، ومستشفيات

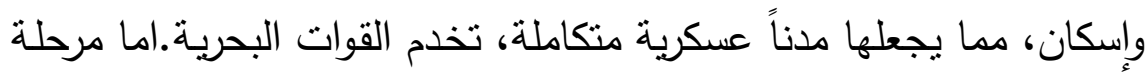

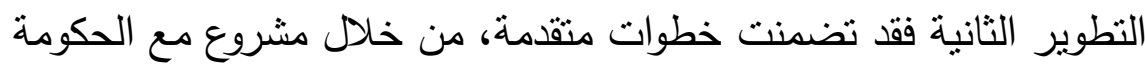

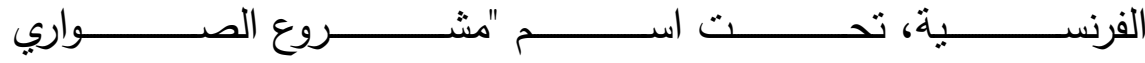

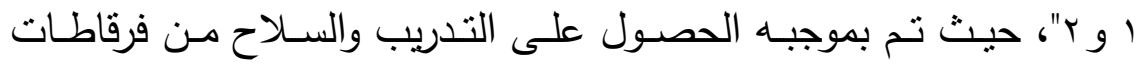

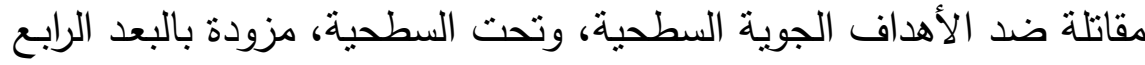

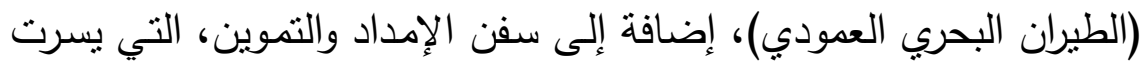

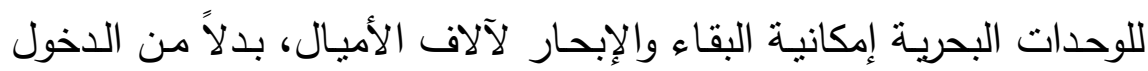

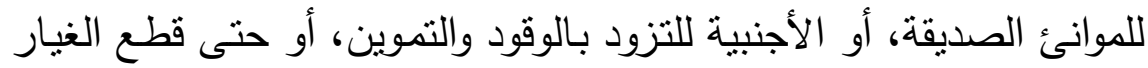

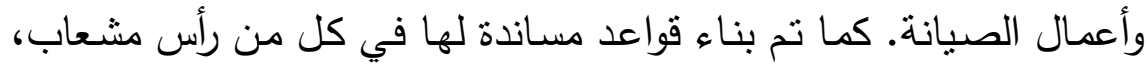

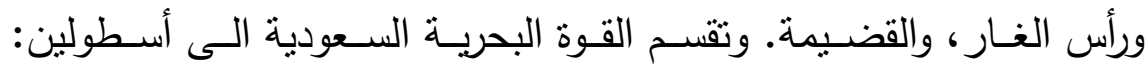

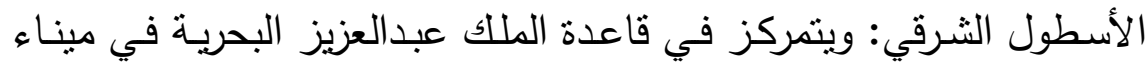

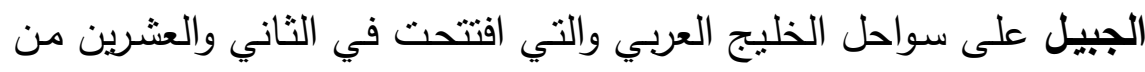

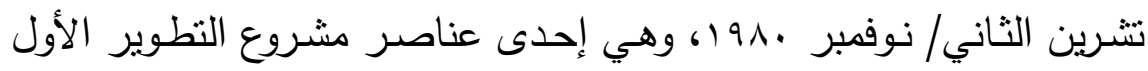

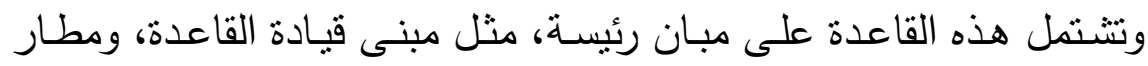

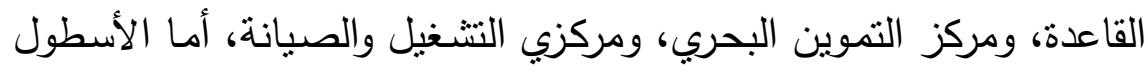

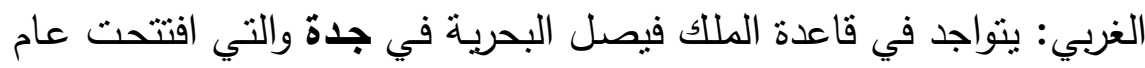

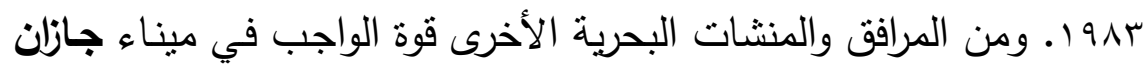

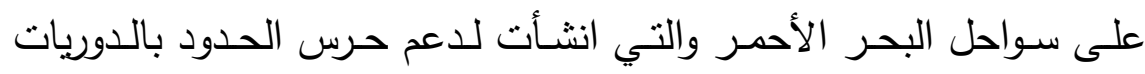

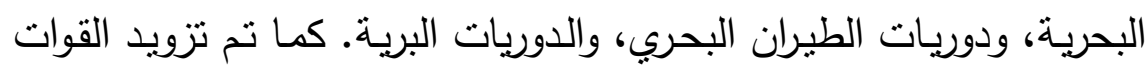

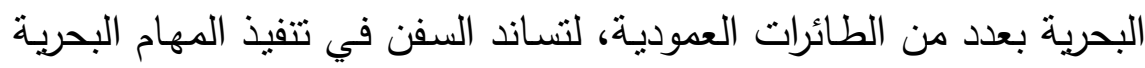

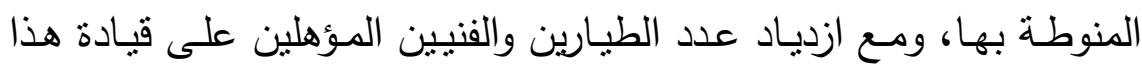

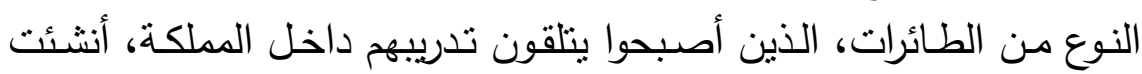

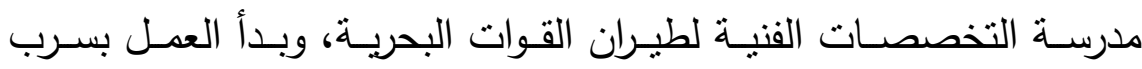

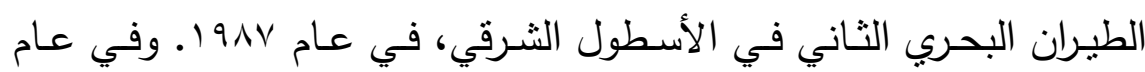


ع191 نم إنشاء إدارة شؤون الطيران بقيادة القوات البحرية في الرياض. وفي

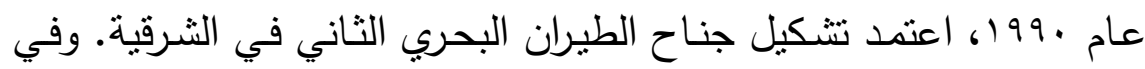
بدايـة عـام 1990 تـم اسـتلام مشـبهين للطـائرات العدوديـة (سـوبر بومـام) و (الدولفين)، لأغراض التدريب(^).

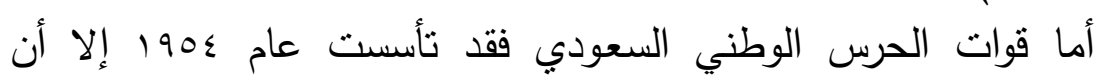

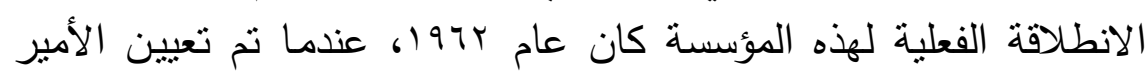

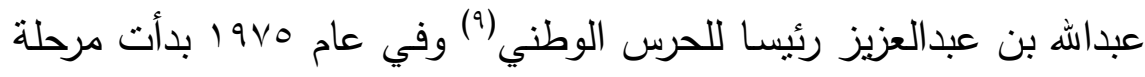
جديدة، كانت نقلة أخرى للحرس الوطني، عندما بدأ برنامج تطويره؛ وقد الداف

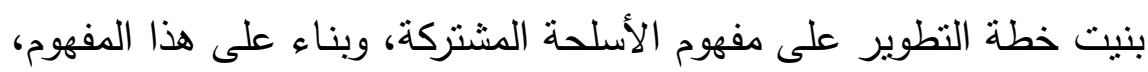
تم تأسيس كتائب الأسلحة المشتركة التي كانت نواة لألوية المشاة الآلية والتي تتمتع بالعديد من الخصائص والقدرات القتالية. كما تمّ تشكيل العديد من وحدات الأمن الخاصة، ووحدات الإسناد مثل الهندسة، والإمداد

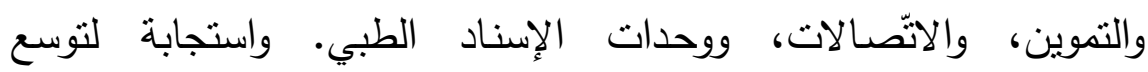
التظظيمات العسكرية وتطورها، استحدث منصب نائب رئيس الحرس الوطني

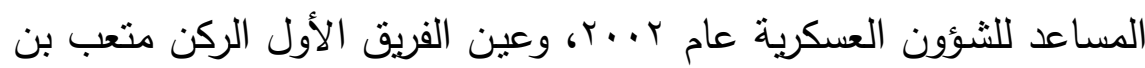

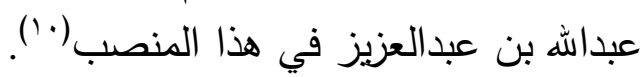

r- الإمكانات القتالية للقوات المسلحة السعودية تعد القوات المسلحة السعودية اكبر قوة عسكرية في دول مجلس التعاون الخليجي من حيث العدد والعدة والكفاءة القتالية، وترتيب الجيش السعودي

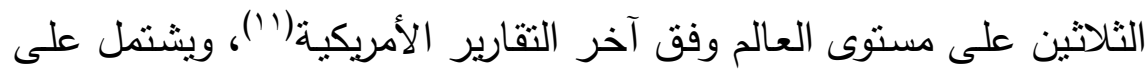

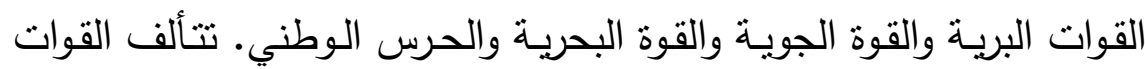

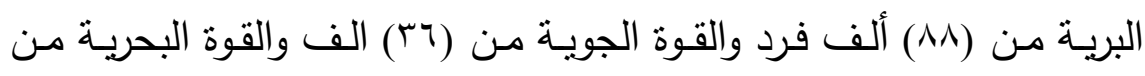
(10) ألف والحرس الوطني من (... (1) الف، وبالتالي فان القوات المسلحة 


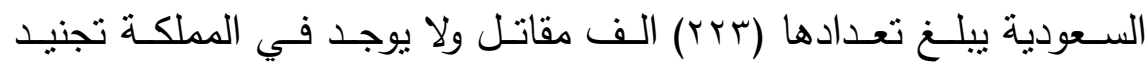

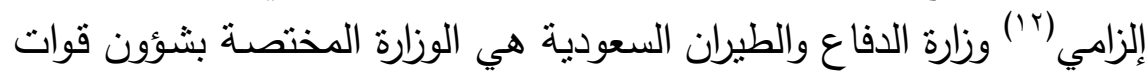

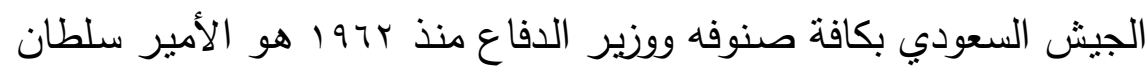

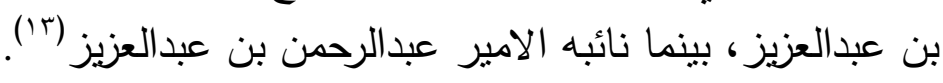
لاشك أن الإمكانات الاقتصادية للمملكة العربية السعودية هيئت ميزة في لائي

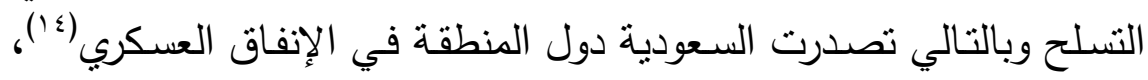

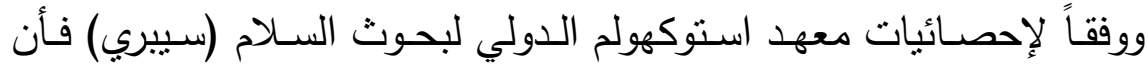
السعودية بقيت لسنوات عدة أكبر دولة بالنسبة للإنفاق العسكري في المنطقة

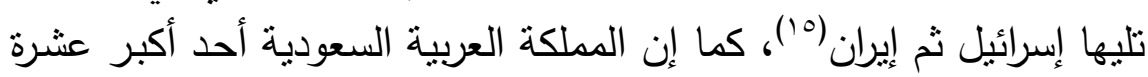

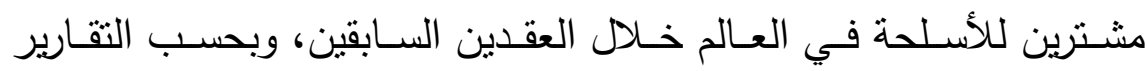
الصـادرة عن معهد استوكهولم الدولي لبحوث السـلام (سيبري) فان المملكة

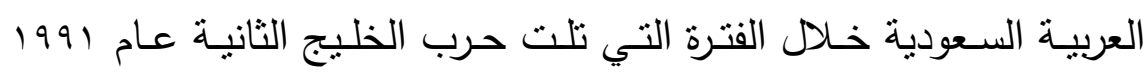
وحتى الآن تجاوز إنفاقها العسكري (•مب) مليـار دولار والجدول رقم (1) يوضتح تفاصبل ذلك.

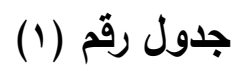

الإنفاق العكري في المملكة العربية السعودية (مليار دولار)(19)

\begin{tabular}{|c|c|c|c|}
\hline الإنفاق & السنة & الإنفاق & السنة \\
\hline 19,9 & $r \ldots$ & $r \uparrow, \Lambda$ & 1991 \\
\hline
\end{tabular}




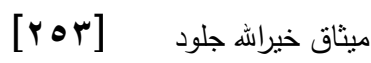
القدرات العسكرية للمملكة العربية.

\begin{tabular}{|c|c|c|c|}
\hline$r, r$ & $r \ldots 1$ & $1 \varepsilon, 0$ & $199 r$ \\
\hline $1 \Lambda, \Lambda$ & $r \ldots r$ & $1 \tau, r$ & $199 r$ \\
\hline $19, r$ & $r \ldots r$ & $1 \varepsilon, r$ & $199 \varepsilon$ \\
\hline $19, r$ & $r \ldots \varepsilon$ & $1 r, r$ & 1990 \\
\hline- & $r \ldots 0$ & $1 r, 9$ & 1997 \\
\hline$r 9$ & $r \ldots r$ & - & $199 r$ \\
\hline$r r, \Lambda$ & $r \ldots r$ & - & 1991 \\
\hline$r \Lambda$ & $r \ldots \Lambda$ & - & 1999 \\
\hline
\end{tabular}

ولمعرفة قدرة أي جيش لابد من استعراض الأسلحة التي يمتلكها هذا

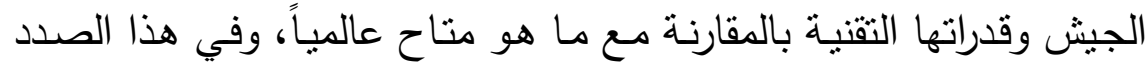

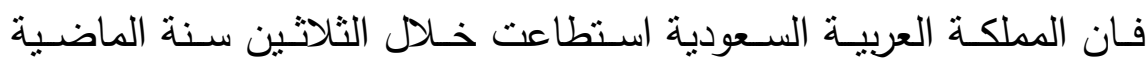
الحصول على العديد من الأسلحة المتطورة والتي كانت انعكاسـا لعلاقاتها الجيدة مـع الدول الغربية، وفيما يلي استعراض لأهم الأسلحة التي تمتلكها القوات المسلحة السعودية بكافة صنوفها:

- القوات البرية -

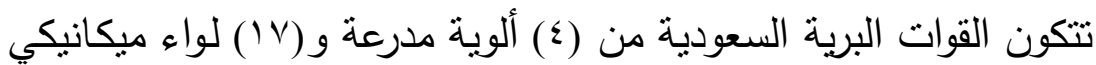

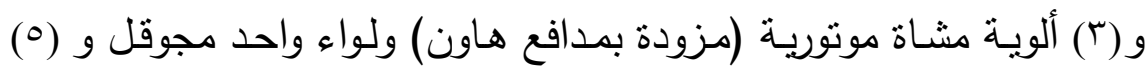

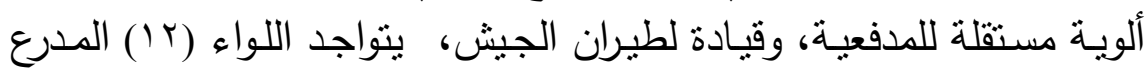

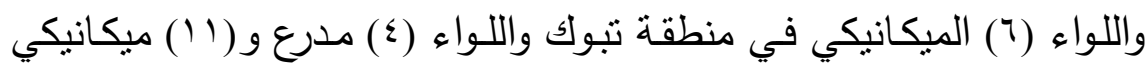
في منطقة خميس مشيط، واللوائين الثامن والعشرين الميكانيكيين في منطقة ولئة

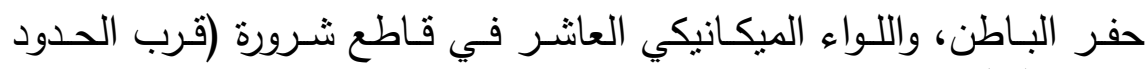

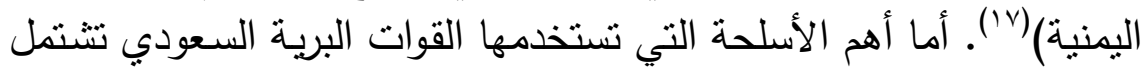




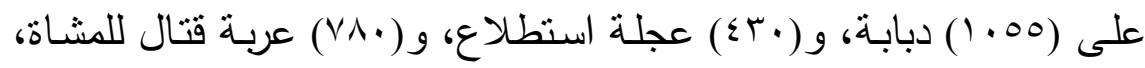

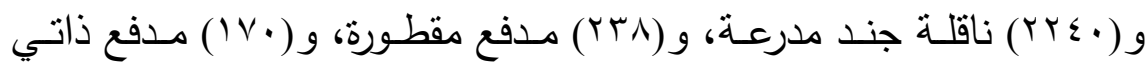

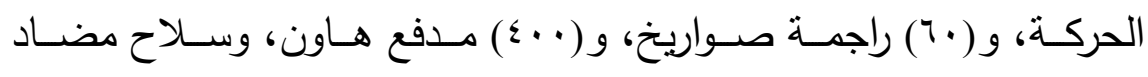

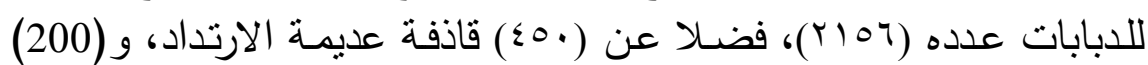

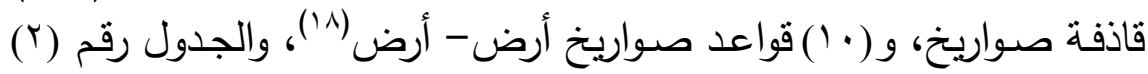
يوضح تفاصيل أكثر عن اسلحة القوات البرية السعودية.

جدول رقم (r) : أسلحة القوات البرية السعودية(9)

\begin{tabular}{|c|c|}
\hline 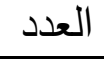 & 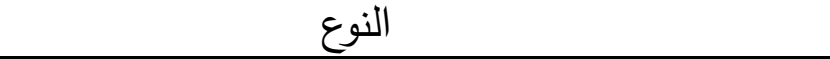 \\
\hline 1.00 & دبابة معركة مختلفة المناشئ والطراز أهمها دبابة "ابرامز" \\
\hline irV. & عجلة مشاة آلية مدرعة و دبابة محددة الإمكانيات \\
\hline M19. & عجلة قتال مشاة مدرعة \\
\hline rth & قطعة مدفعية \\
\hline iv. & قطعة مدفعية ذاتية الحركة \\
\hline 7. & راجمة صواريخ \\
\hline 1. & قاذفات صواريخ أرض - أرض GSS-2 \\
\hline 70. & قاذفة صواربخ منوسطة \\
\hline r.o. & سلاح موجه مضاد للدروع \\
\hline 00 & طائرة عمودية للنقل متواجدة بصورة دائمة مع القوات البرية \\
\hline $1 \ldots$ & قاذفة صواريخ أرض-جو \\
\hline ir & طائرة عمودية مقاتلة AH-64 \\
\hline
\end{tabular}

- القوة الجوية

تحظى القوات الجوية السعودية بوجه خاص باهتمام بالغ ودعم منواصل

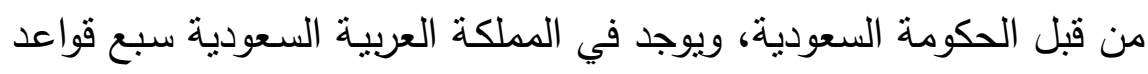

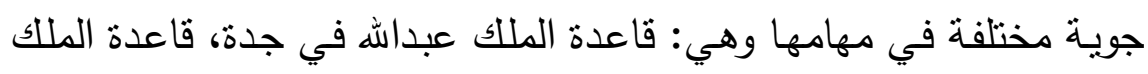

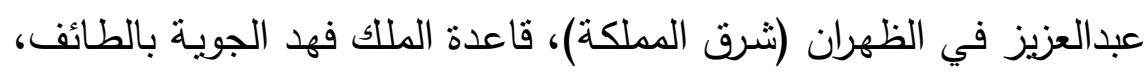
قاعدة الملك فيصل الجوية بتبوك، قاعدة الملك خالد الجوية بخميس مشيط، 
قاعدة الريـاض الجويـة، قاعدة الأمير سلطان الجويـة بـالخرج (أكبر قاعدة

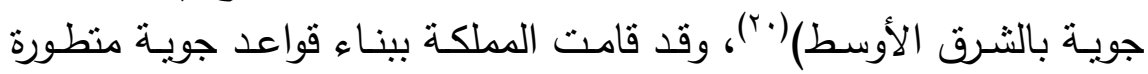

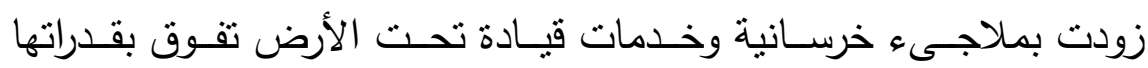
ملاجىء بعض دول حلف شمال الأطلسي، إذ يسمح كل ملجىء بتخزين

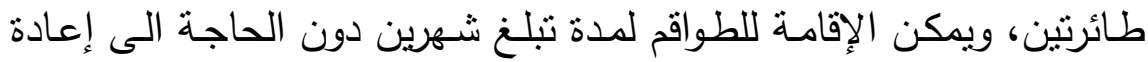
التموين، ومن الجدير بالذكر أن الدول ذات الميزيانيات العسكرية الصغيرة

ليس باستطاعتها تحمل تكاليف مثل هذه الملاجىء المتطورة(r)."

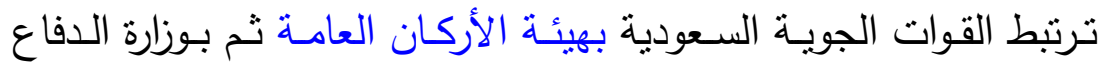

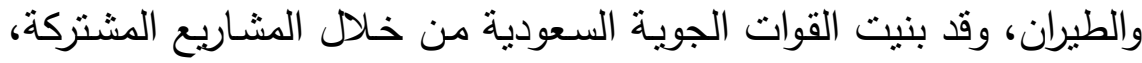
وكان أول هذه المشاريع التي تم تتفيذها مشروع (البساط السحري) الذي

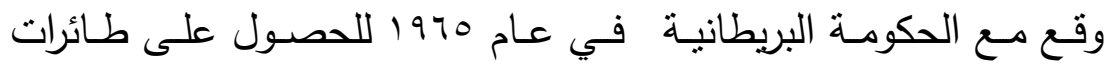

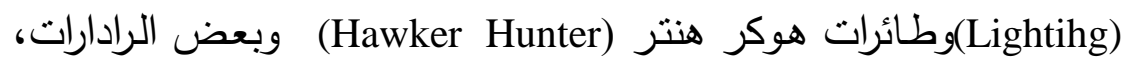
والصواريخ المضادة للطائرات، تبع ذلك المشروع تأسيس بنية تحتية تعتمد على بناء خمس قواعد جوية أساسية حديثة، تضم كل منها كافة التسـيلات

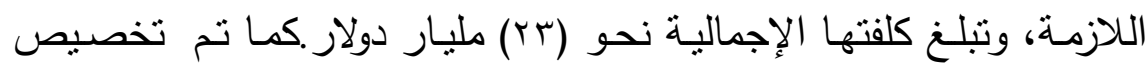
( ( ) مليار دولار لبناء مدن مجمعات عسكرية كبرى مخصصة لسكن أفراد القوات الجويـة. وفي بدايـة السبعينيات بـدأ العمل بمشروع (صقر السـلاح) مع الحكومة الأمريكية لتزويد السعودية بـ ( • (1) طائرة من طراز - F-5E-B)

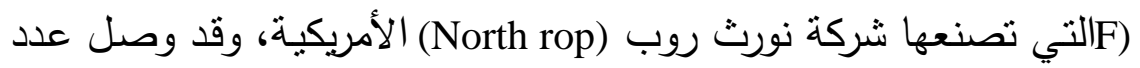

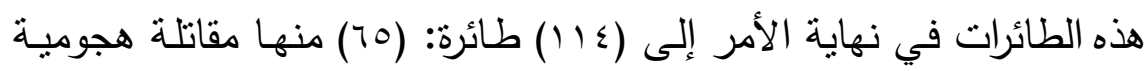

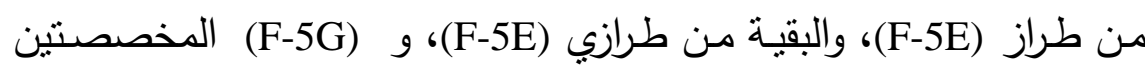

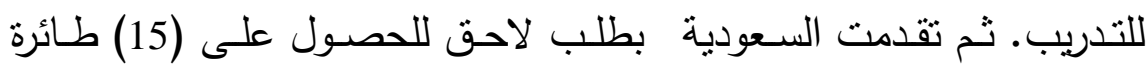

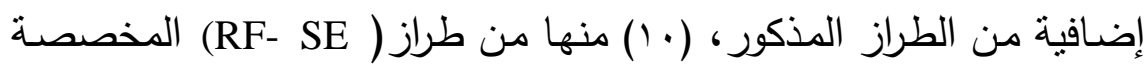

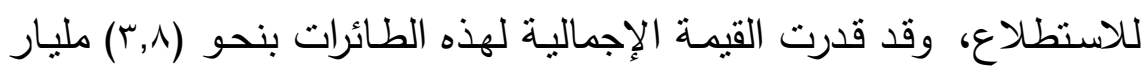


دولار تتمل كلفة قطع الغيار والتدريب. ثم تـلا ذلك مشروع (شمس السـلام)

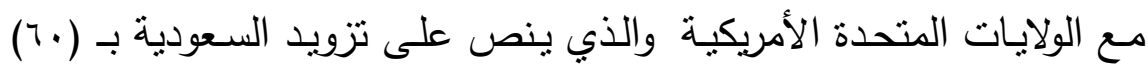
طائرة طراز (F-15 CID) من صنع شركة ماكدونال دوغلاس (McDonnell)

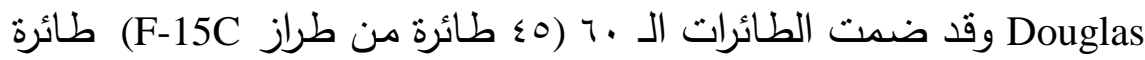
من النموذج القتالي و 10 طائرة من طراز (F-15D) المخصصة للتدريب. وتم

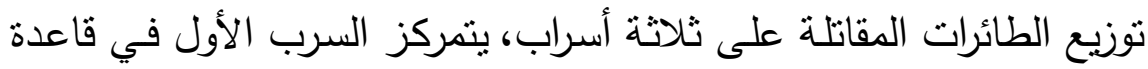
(الظهران) الجوية، والسرب الثاني في الطائف والسرب الثالث في منطقة (خميس مشيط) في جنوب غرب البلاد (rr) وهذه الطائرات مزودة بخزانات

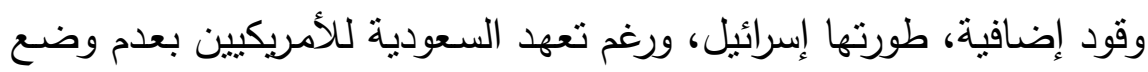
هذه الطائرات في القواعد الثمالية القريبة من إسـرائيل، إلا أن المملكة لـ لم تلتزم بهذا الاتفاق(rr(r)، ثم تلا ذلك عقد مشروع (حارس السلام) لتزويد سلاح الطيران بخمس طائرات للإنذار المبكر من طراز (بوينغ إي ـ س أ اواكس)

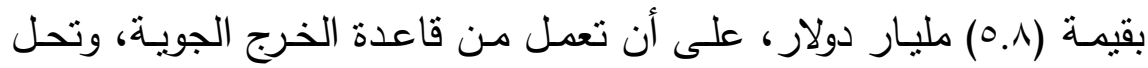

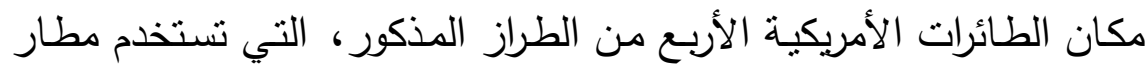

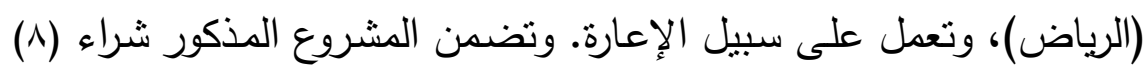

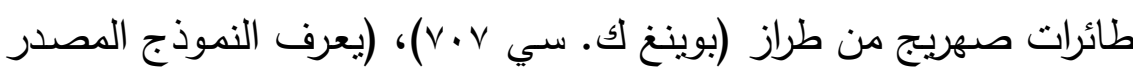

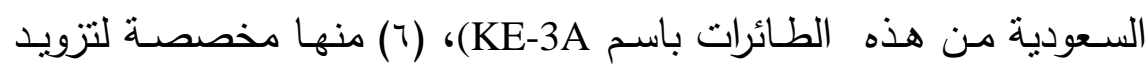

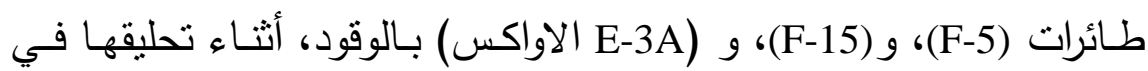

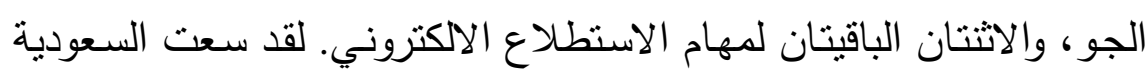

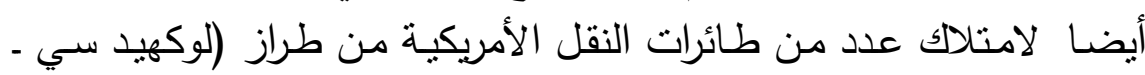

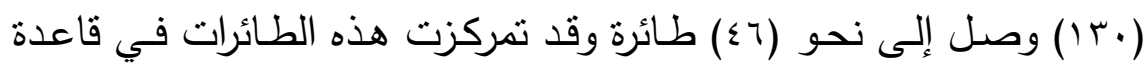
جدة ويجري استخدامها في المهام اللوجستية، على ان يتم تجهيز بعض هذه هذه

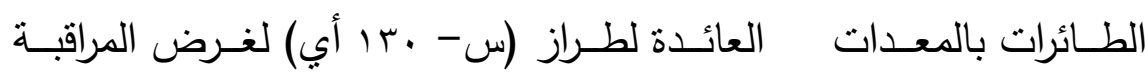
الالكترونية. في ايلول /سبتمبر 1910 جرى توقيع مذكرة تفاهم بين السعودية والحكومة البريطانية للحصول على صفقة أسلحة بريطانية أطلق عليها اسم 


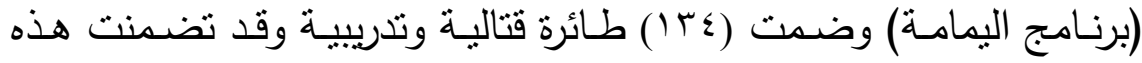

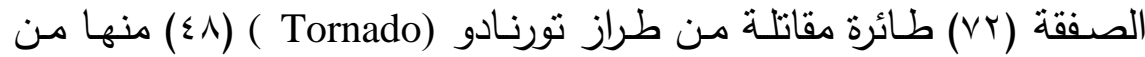
طراز (IDS) القاذفة المعترضـة، و (؟r) مقاتلة معترضـة متعددة المهام من

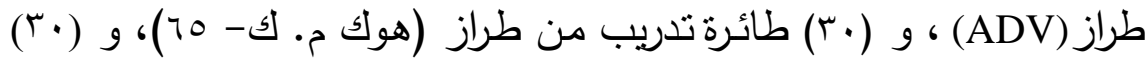
وطائرة تدريب من طراز (بيلاتوس بي - سي - 9) وطائرتا تدريب نفاثتان

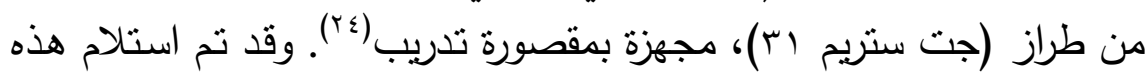

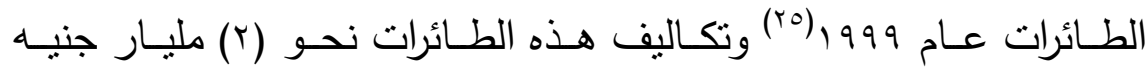

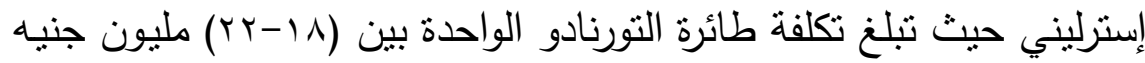

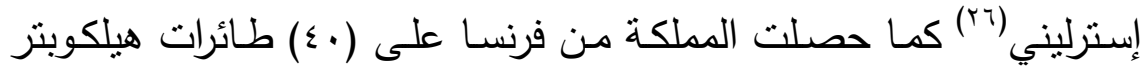

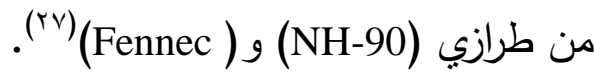
ولو أردنا تقيم مدى فاعلية سـاح الحو السعودي فانه يتكون من (rیمب) طائرة مقاتلة تعد نخبة القوة القتالية للجيش السعودي، و و هذه الطائرات هي

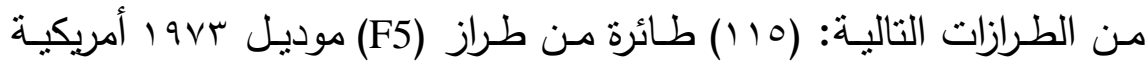

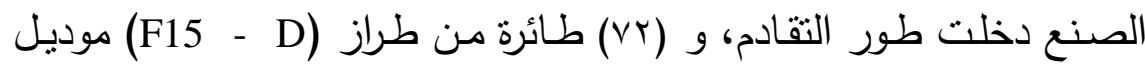

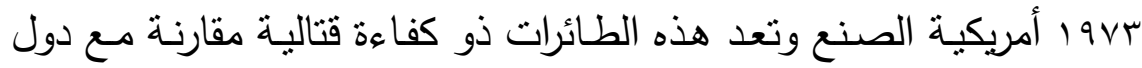

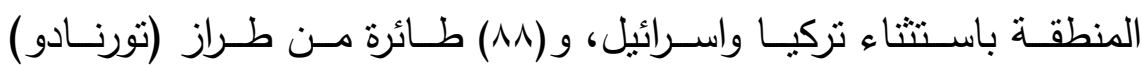
Tornado

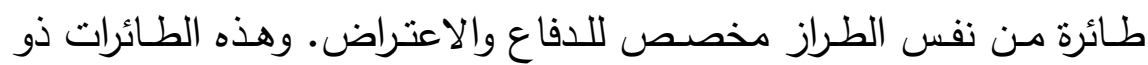

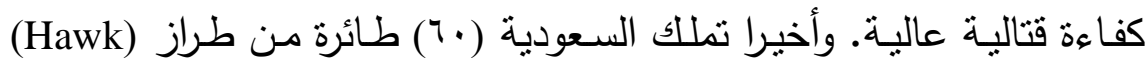
بريطانية الصنع وهي طائرة تدريب قتالية(^^). تتميز مقاتلة (F-15E) بأنها

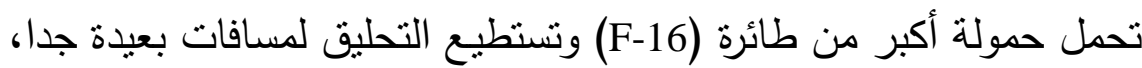

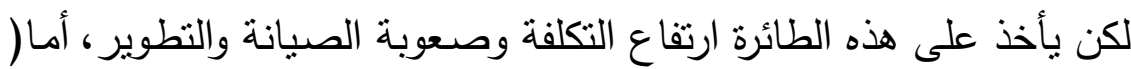

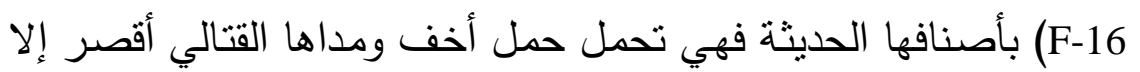
أنها أقل تكلفة وصيانتها سهلة وهو ما يفسر بيع المئات من تلك الطائرة 
للكثير من الدول، وبهذا يمكن القول إن السعودية بنت ستراتيجيتها في

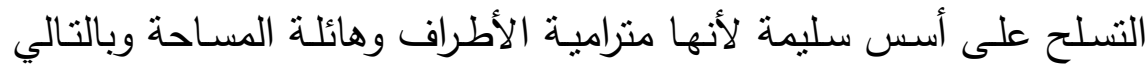

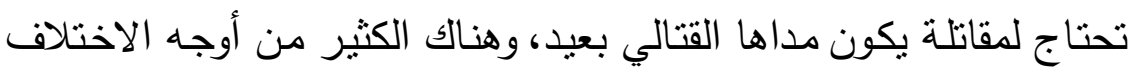

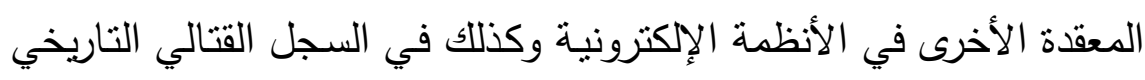

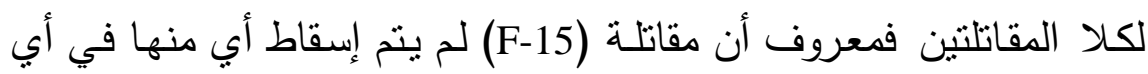

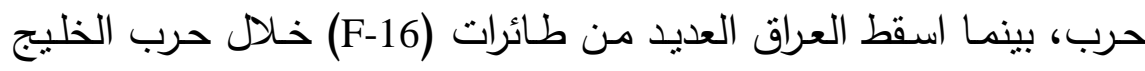

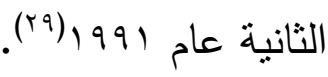

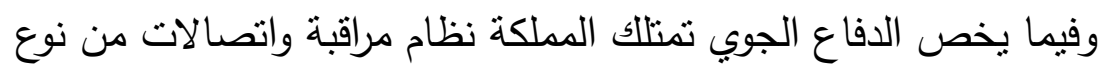

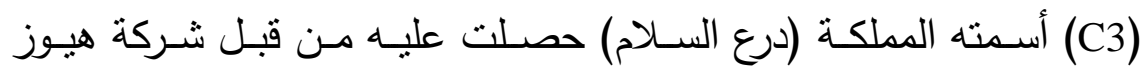

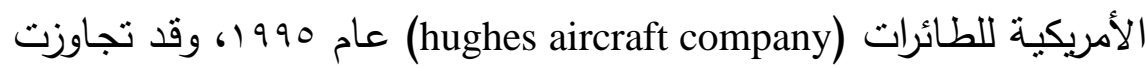
تكاليف نصب هذا النظام المليار دولار ويتضمن هذا النظام عدد من مراكز

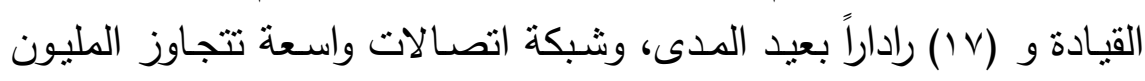

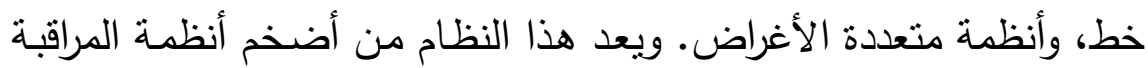

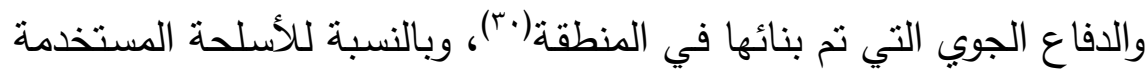

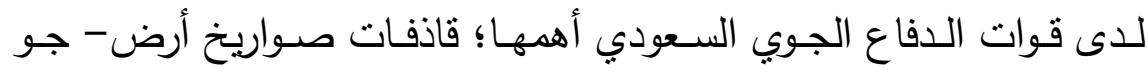

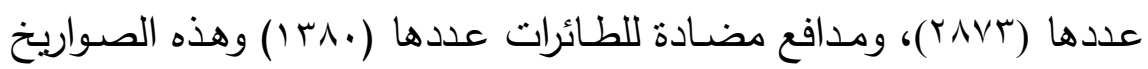

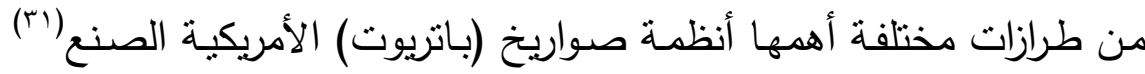

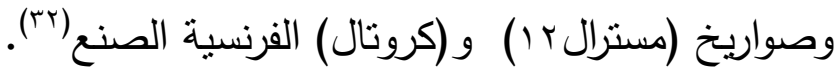

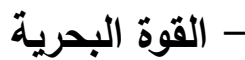

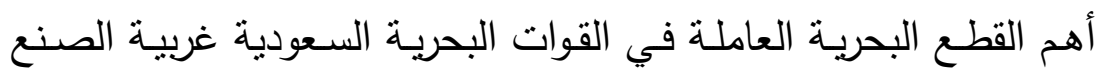

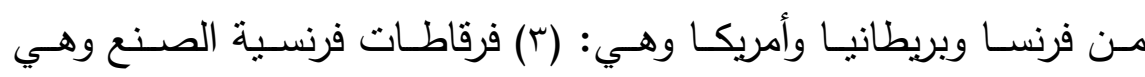

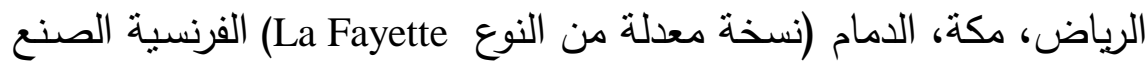

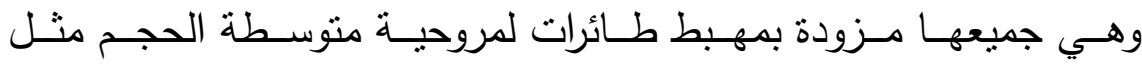




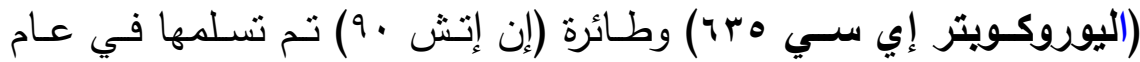

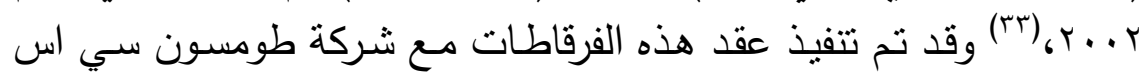
اف Thomson CSF) الفرنسية اذ تم تجهيز هذه الفرقاطات ضمن صفقة

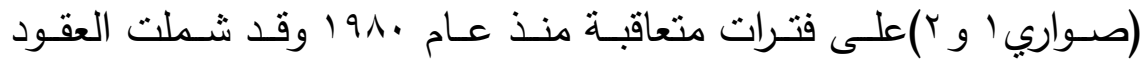

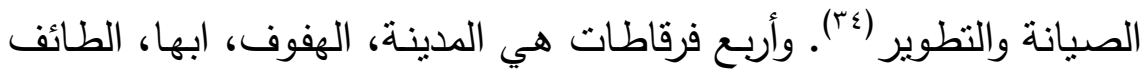

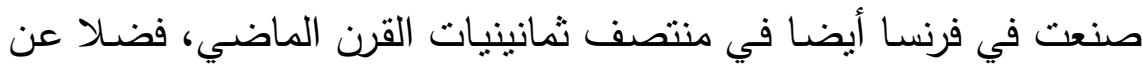
أربع زوارق نوع البدر، اليرموك، حطين، تبوك صنعت في الولايات المتحدة

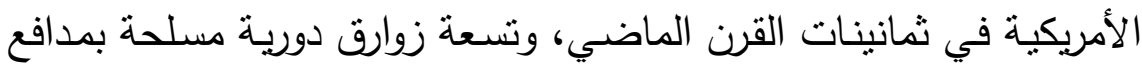

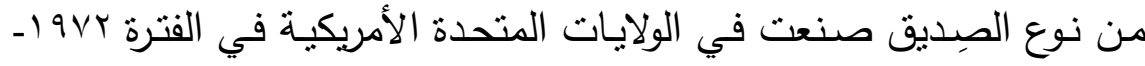
•919، وثلاث كاسحات الغام بريطانية الصنع هي الجوف، شقرا، الخرج، وهذه الكاسـات مصنعة مـن صـائح البلاستيك المقوى ويرتكز تصميمها على الفئة المستخدمة في البحرية البريطانية لكن تم تطويرها لتلائم البحرية السعودية، وقد ثم تصنيعها من قبل شركة (فوسبير ثورينكروفت البربطانية

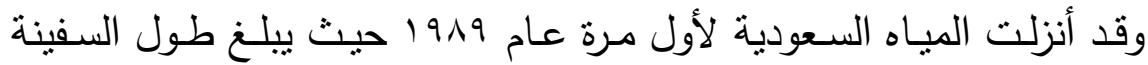

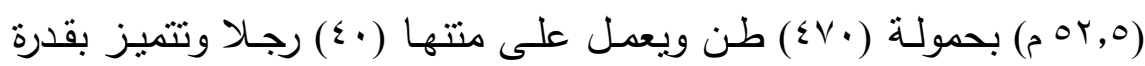
فائقة على التحرك ببطى وبدون بهون ضجيج، وتحتوي على نظم قيادة عالية

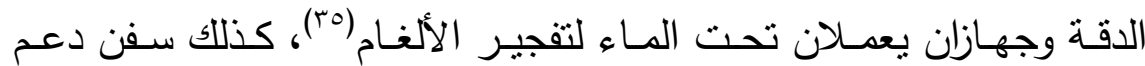

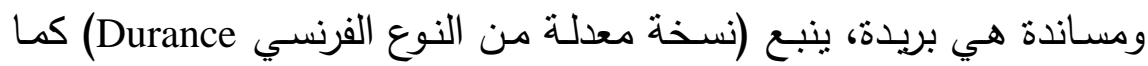

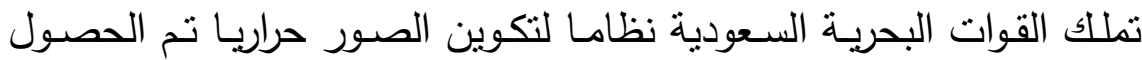
عليه من شركة فلير سيستمز (Flir Systems) الأمريكية(بr).

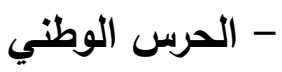
تتكون قوة الحرس الوطني مسن (9) فرق عسكرية موزعـة على أمساكن

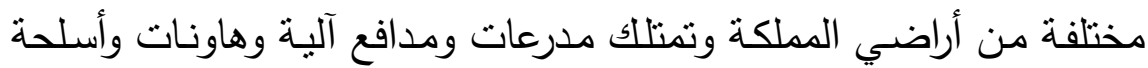


متوسطة وخفيفة، وبالتالي فان تسليح الحرس الوطني متوافق مـع المهام

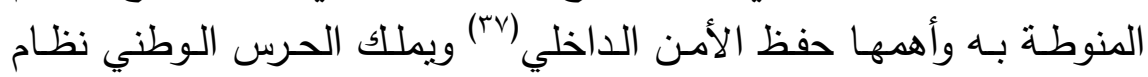

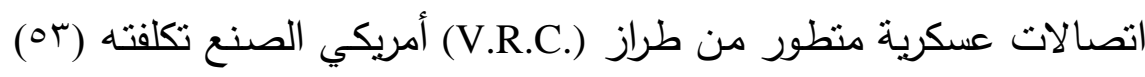

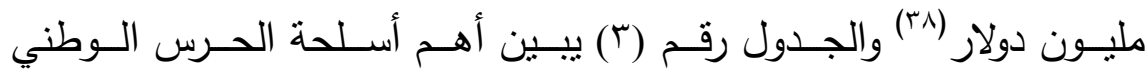

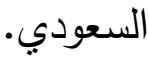

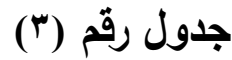

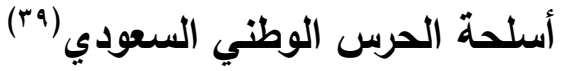

\begin{tabular}{|c|c|}
\hline $111 \mathrm{~V}$ & عجلة ذات تدربع خفيف \\
\hline 19. & عجلة إسناد أداري \\
\hline$\wedge 1$. & عجلة مشاة مدرعة \\
\hline$\vee$. & قطعة مدفعية ذاتية الحركة \\
\hline 111 & سلاح موجه مضاد للاروع، \\
\hline vr & مدفع هاون \\
\hline
\end{tabular}

عند الحديث عن القدرة العسكرية لأي دولة، فان استعراض حجم القوات

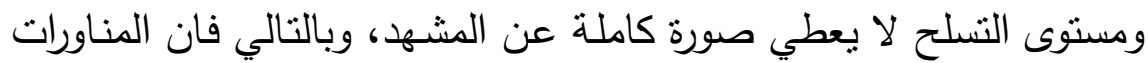

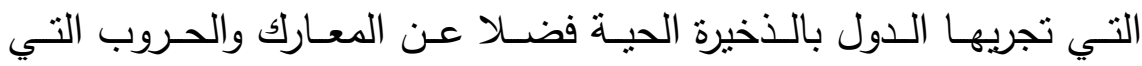
تخوضها كل ذلك كفيل بكثف المستوى القتالي الحقيقي، وقدر تعلق الأمر بالمملكة العربية السعودبة فقد قام الجيش السعودي بعدة مناورات بالذخيرة

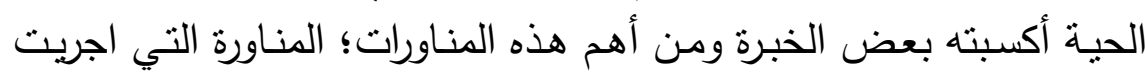

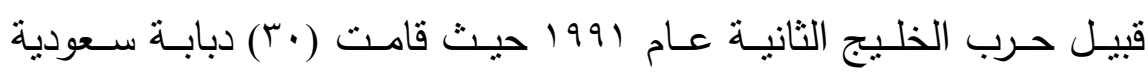
بإطلاق ذخيرة حية على أهداف عراقية وهمية وقد شاركت القوات الأمريكية

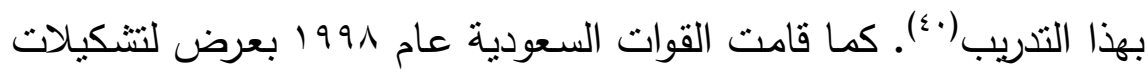
القوات المسلحة بعد الحصول على الدبابـة الأمريكية الصنـع ابرامز وناقلة

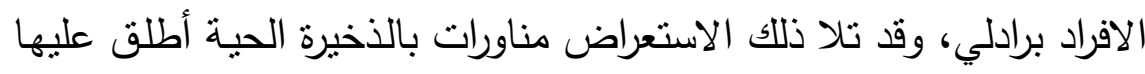


اسم (سـهم النصر ( ) حيث شـاركت دبابات ابرامز (M1) و (M2) وقد تمت هذه المناورات دون مشاركة أجنبية وقد وصفها المراقبون في تلك الفترات داتهات أنها

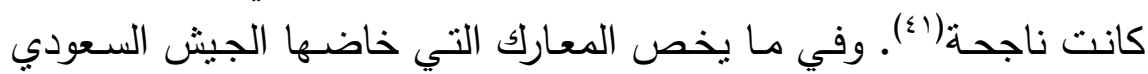

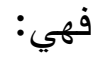
- حـرب توحيـ المملكـة العربيـة السـودية (r ـ19 - 1926 (1) وكانـت حرب بسيطة لا يمكن القياس عليها الآن.

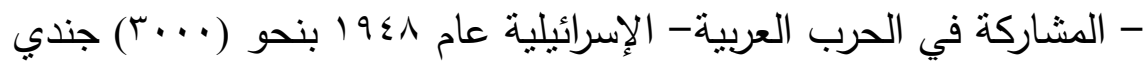
مشاة سعودي وقد كان الأداء العربي عموما ضعيفاً.

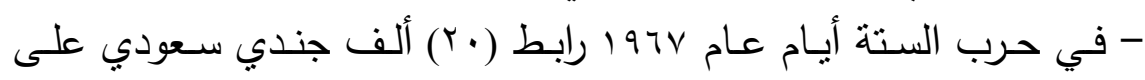
الجبهة الأردنية لكنهم لم يشاركوا فعليا في القتال.

- خوض معركة الوديعة عند احتلال جيش الجمهورية اليمنية الاشتراكية لمنطقة "الوديعة" عام 979 19، وقد استطاع الجيش السعودي هزئ هزم القوات

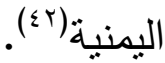

- مشاركة البحرية السعودية في الحرب التي اندلعت في شبه القارة الهندية

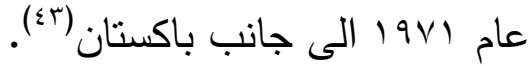

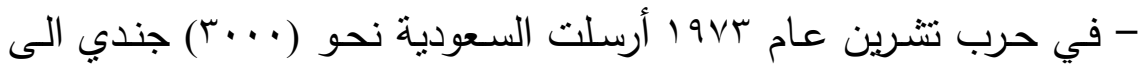

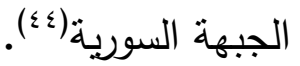

- المشــاركة في حـرب الخلـيج الثانيـة بجميـع صـنـوف القوات المسـلحة

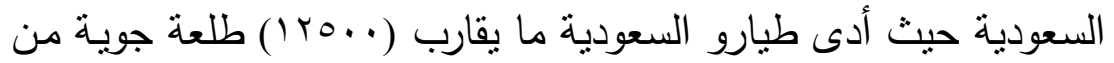

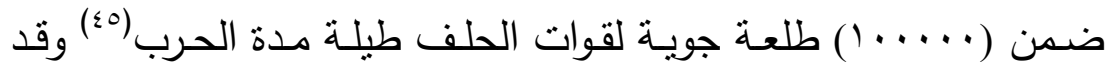
كانت هذه الحرب من أهم التجارب التي خاضها الجيش السعودي وذلك لشراستها وكثافة النيران التي استخدمت فيها، وقد كانت سبباً في توجه

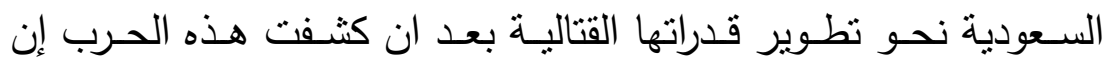
الجيش السعودي غير قادر على حماية حدود المملكة بمفرده(؟ء). 
- المشـاركة في مكافحـة القرصنة في بحر العـرب وخليج عدن منذ عـام $\left.{ }^{(\Sigma V}\right)_{Y} \ldots \Lambda$ - خوض عدة معارك مع الحوثيين أواخر عام 9. . ب وقد شاركت في هذه

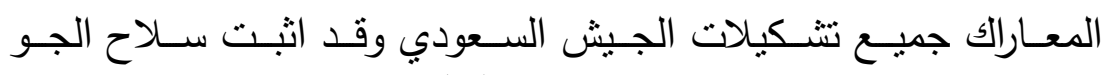

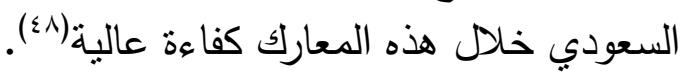

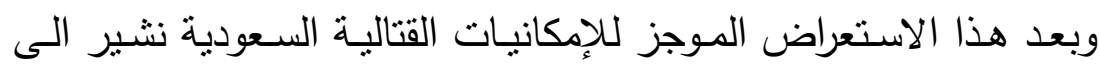

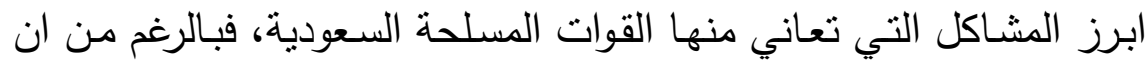
المملكة العربيـة السعودية تمثلك العديد من الأسلحة الحديثة ذات القدرات

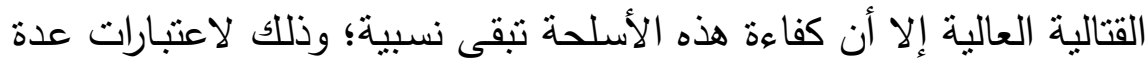

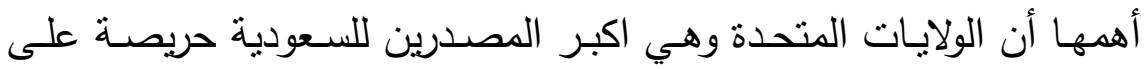

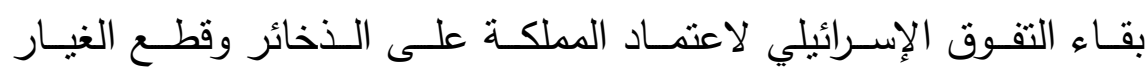

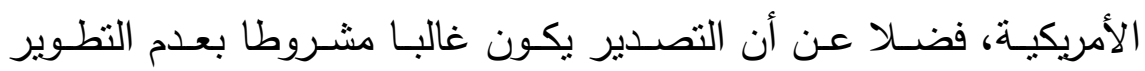
(خاصـة خزانـات وقود الطـائرات) كمـا ان التصـدير يكون احينـا مشـروطاً باستخدام خبـراء وفنيين مـن الجهة المصدرة، فإذا أرادت المملكـة استخدام

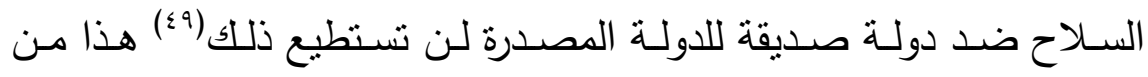

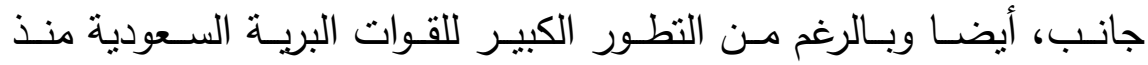

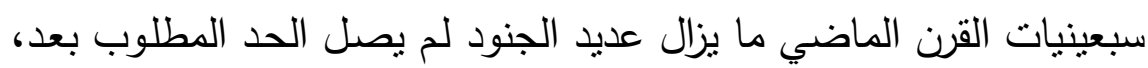
إذ لايوجد في المملكة تجنيد إلزامي كما ان الطائرات ولاسيما طائرات (F15) بيعت للسعودية بسعر اكبر من السعر الذي بيعت لإسرائيل مـع أن خزانها

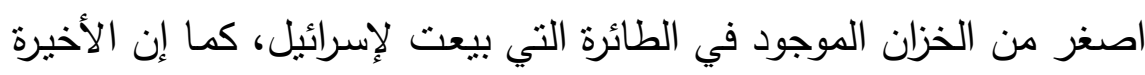
يسمح لها بوضع خزان إضافي ولايسمح للجانب السعودي بان تحمل الطائرة بأكثر من (r ا) طن من القنابل إلا بإذن خاص من وزارة الدفاع الأمريكية،

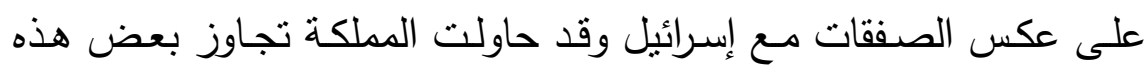

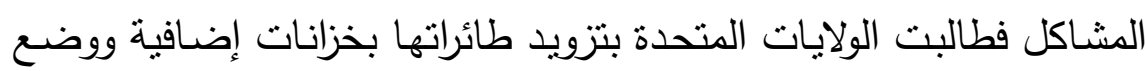

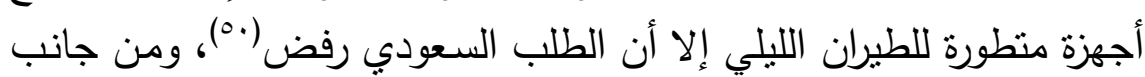


آخر تمثنل مسـاحة المملكة الثاسـعة مشكلة للقوات الجويـة والدفاع الجوي ولاسيما تغطية الرادارات، بالتالي يجب وضـع الرادارات في مناطق مرتفعة

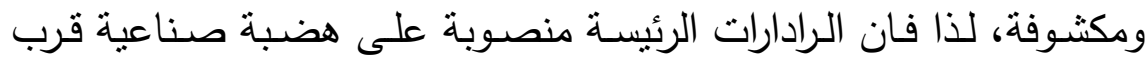
قاعدة الظهران وبهذا تكون مهمة الحفاظ على المجال الجوي السعودي من قبل سـلاح الجو شبه مستحيلة(1) وأخيراً بالرغم من الحدود المائية الكبيرة

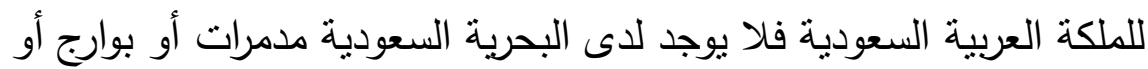

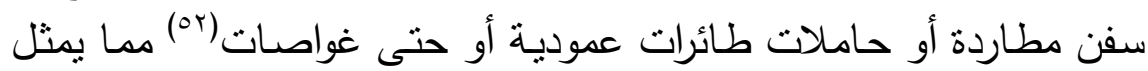
خلا في إستراتيجية تسليح القوة البحرية السعودية.

\section{r- واقع التصنيع العسكري في المملكة العربية السعودية}

بتسـارع وتيـرة الحـروب والأزمـات العالميـة، تشـهـ مؤسسـات الصــناعة

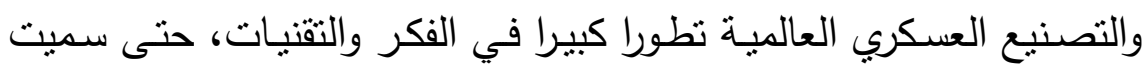

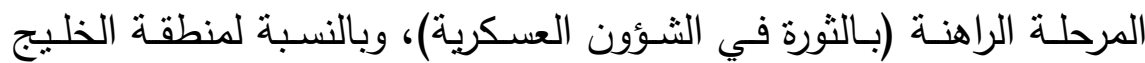
العربي قد بدأت بوادر التصنيع العسكري بشكل أسرع وتيرة بعد حرب الخليج

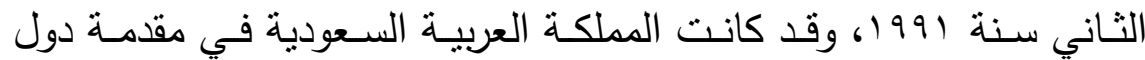
الخليج العربي في سعيها نحو تطوير قدراتها في التصنيع العسكري(بهان. تعد السعودية من أوائل الدول العربية التي فكرت بإنشاء تصوبر تصنيع

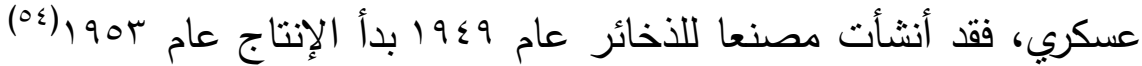
كما كانت الثريك الرئيس لمصر في تأسيس الهيئة العربية للتصنيع عام 19v0 فضلا عن قطر والإمارات، غير أن انهيار الهيئة عام $19 \vee 9$ على التى اثر الاتفاقية المصرية- الإسرائيلية أدى بالسعودية الى أن تعيد تقييم أهدافها 
في مجال التصنيع العسكري ومس بداية ثمانينيات القرن الماضي وضعت

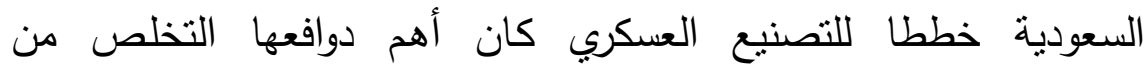
الصعوبات المتكررة في كل صفقة عتاد أو سلاح بسبب اللوبي الإسرائيلي

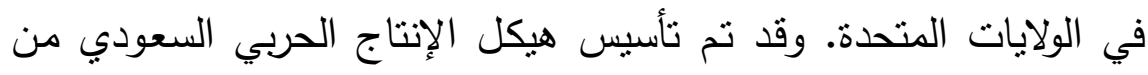
مؤسستين رئيستين هما: الهيئة العامة للصناعات الحربية ومؤسسة

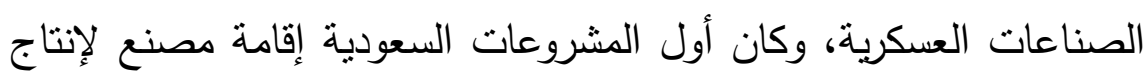
البندقية الهجومية من طراز (G13) وذخائرها بواسطة شركة (هيكلر وكوخ) وفي عام 1910 تم توقيع برنكول التعاون السعودي البرازيلي في مجال إنتاج الأسلحة المشترك(00) كذللك تم الاتفاق مع الولايات المتحدة على إنى إنتاج

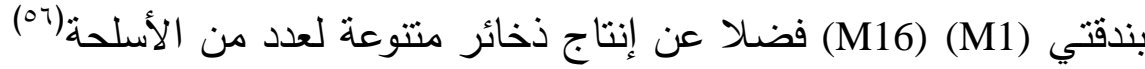
وقد شهدت الصناعات العسكرية السعودية عدة تطورات حتى وصلت إلى إلى تحقيق الاكتفاء الذاتي في الأسلحة الثخصية. وقد نتج عن إقامة الصناعة العسكرية السعودية العديد من الآثار التتموية، إذ شهدت مدينـة الخرج التهاء

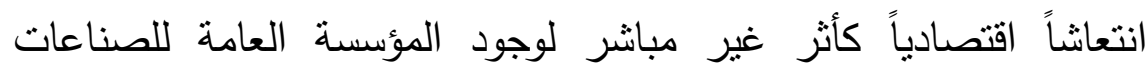
العسكرية فيها، أما في مجال تتمية القوى البشرية في المنطقة فقد أصبحت مدينة الخرج مركز جذب حضاري للمناطق المحيطة بها، حيث حصل فل فئل العديد من المواطنين على وظائف في المصانع العسكرية، وافتتحت مشاريع

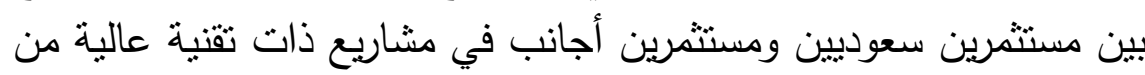

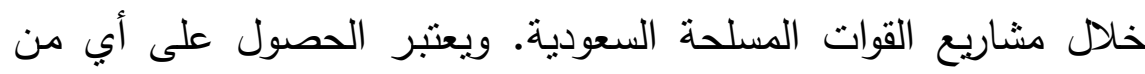
عقود التسليح للقوات المسلحة مشروطاً باستثمار جزء من قيمة العقود بنحو (ب\%\%) في المملكة، وقد طبق هذا المفهوم على مشروع (درع السلام)، تلا

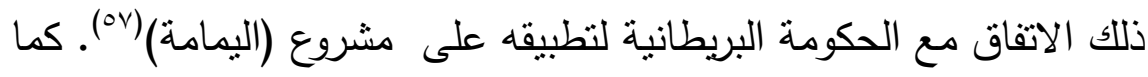

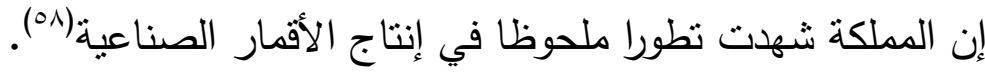
أما أهم الثركات المنتجة للمعدات والذخائر والأسلحة في السعودية: 
ميثاق خيراله جلود

1-شـركة عبداله الفـارس للصناعات التقيلة: تقوم بتصنيع العربـة المدولبـة

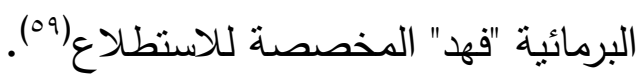

r- شركة الالكترونيات المنقدمـة: تقدم خدمات الفحص وإعـادة التأهيـل لجميع أنظمة الاتصالات والأجهزة الإلكترونية العسكرية، وتصنية ألتونيع أنظمة إلكترونية خاصة لدبابات (M2 ، M1) ولوحات إلكترونية للقنابل الموجهة بالليزر، واستطاعت الثركة تصدير العديد من منتجاتها، كذلك تصنع الراديـو التكتيكي لطـائرة "جـاغوار (Jaguar) وطوافـة بـانثر (Panther) تصنيع وإصـلاح ومساندة أجهزة الاتصالات العسكرية التكتيكية وأنظمة وطانة

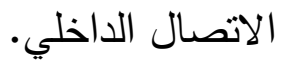

r- شركة السلام للطائرات: تقدم خدمات فنية في صيانة وتشغيل الطائرات وإعـادة تصـميم قمـر القيـادة بالإضـافة إلـى المسـاندة الفنيـة للطـائرات

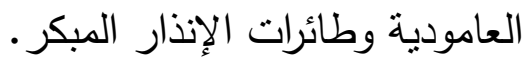

ع- المصنع السعودي لأنظمة الأهداف الالكترونية: يقدم المصنع لعملائه

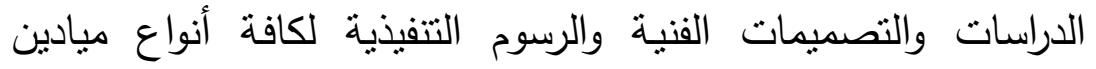

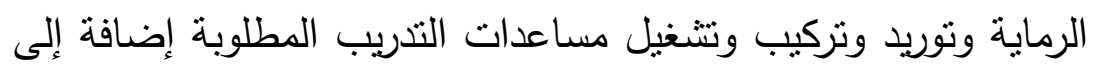

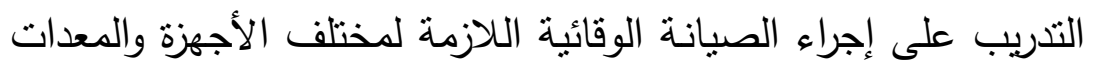

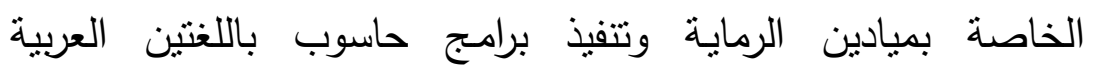
والانجليزية، وقد طور المصنع مجموعة من أهداف التدربب الثابتة والمتحركة. 0- شـركة GD العربيـة المحدودة: وهي شـركة مسـاهمة مـن رجـال أعمـال

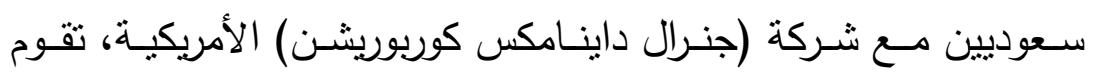
بتشغيل وصيانة وتعديل وتحديث المعدات العسكرية والمدنية والتدريب

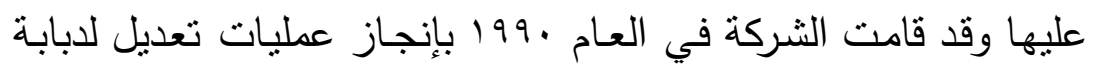
القتال (M60 A1) وتطويرهـا إلى الطراز (M60 A3) وذلك لصـالح 
القوات البرية وفي العام ب99 ا فازت الثركة بمشروع "السيف" لتحديث المدرعات حيث قامت بأعمال لدبابات القتال (M1A2) وفي العام 1999

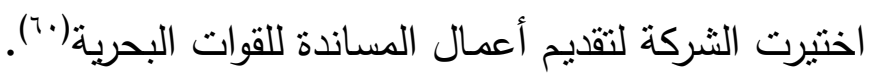
7- مجموعة مصانع العربية: هي مجموعة سعودية متخصصة في تدريع العربـات العسكرية والمدنية وتقوم بصناعـة العربات المدرعة والسيارات العسكرية للمهام الخاصـة وسيارات الإسعاف المصفحة للعناية المركزة.

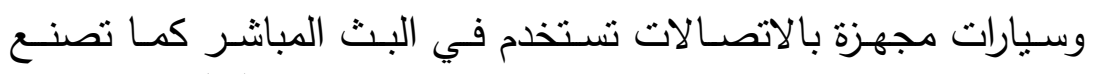
حواجز الطرق وتجهيزات حماية أمنية للبنوك والمنشئات(آل). ـ- التعاون العسكري للمملكة العربية السعودية مع الدول الأجنبية عند الحديث عن التعاون العسكري السعودي مع الدول الأجنبية، فان

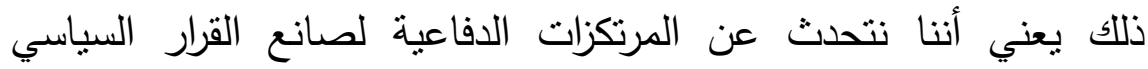

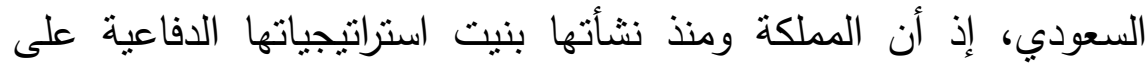
أساس الحماية الغربية عند الضرورة، وفي هذا الصدد فقد وقعت المملكة

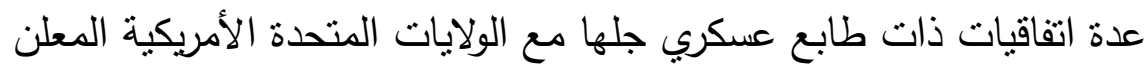

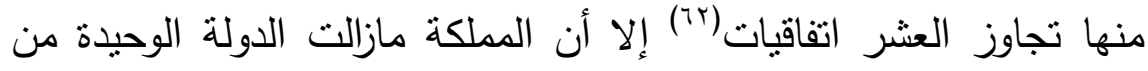

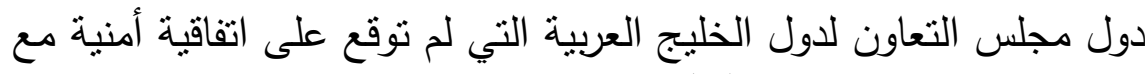
الولايات المتحدة الأمريكية(זٓ) وفي هذا الصدد أثنار الكاتب والصحفي

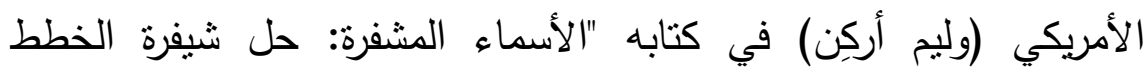

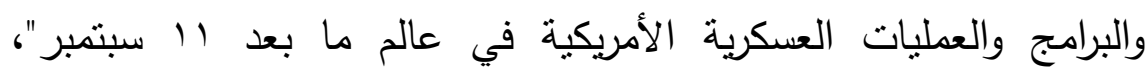

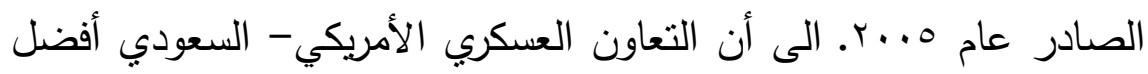

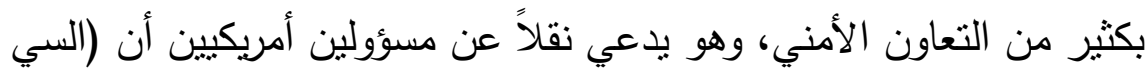
أي إيه) لم تتمكن من تأسيس "علاقة يومية أصيلة" مع الأجهزة الأمنية السعودية، حتى بعد عملية الخبر عام 1997 ضد القوات الأمريكية وأحداث الحادي عشر من أيلول سبتمبر ، إلا أن ذلك لم يمنع من تشكيل قوة تدخل فيل فئل 


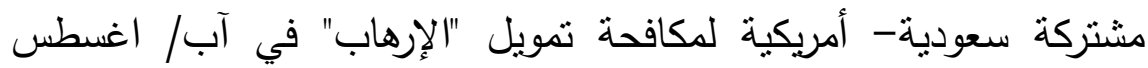

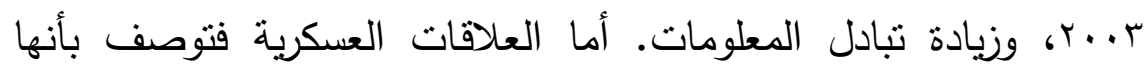

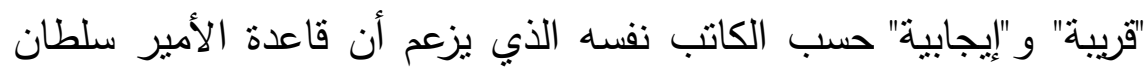

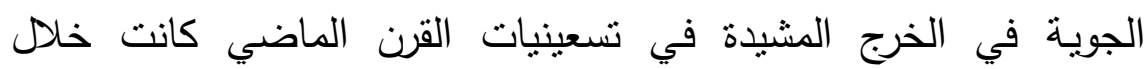

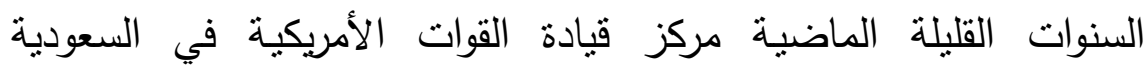
والمنطقة، بالرغم من انخفاض أهميتها كثيراً بعد بناء القاعدة الأمريكية

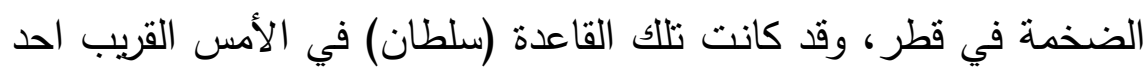

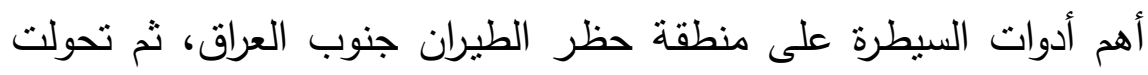

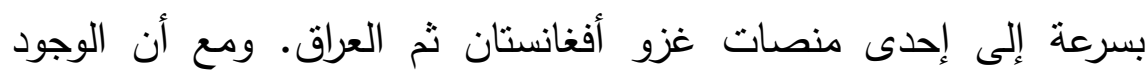

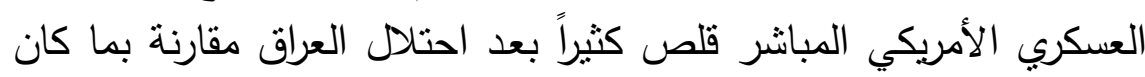

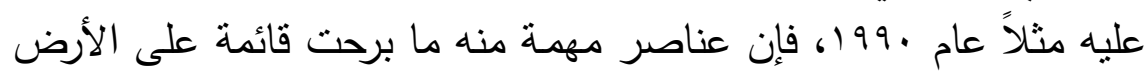

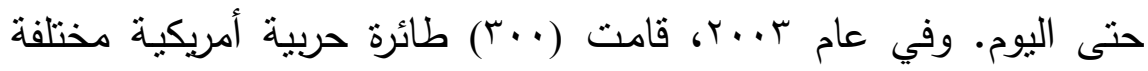

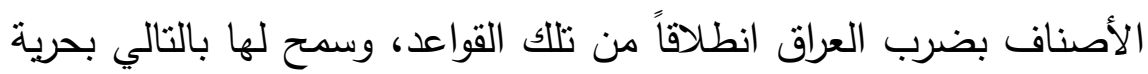

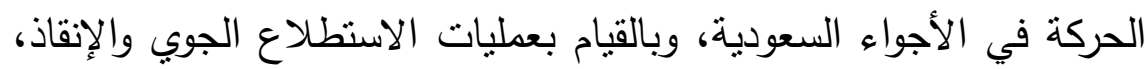

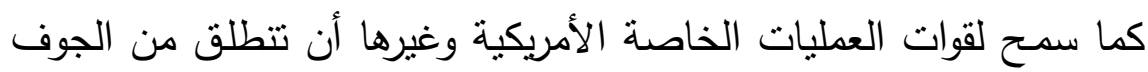

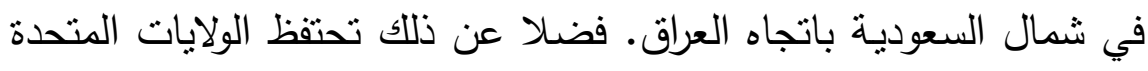

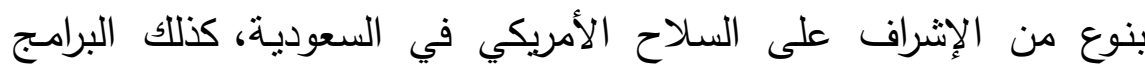

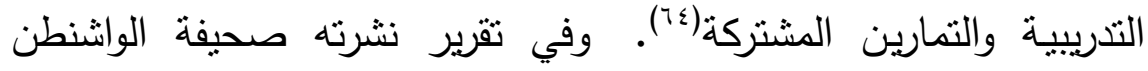

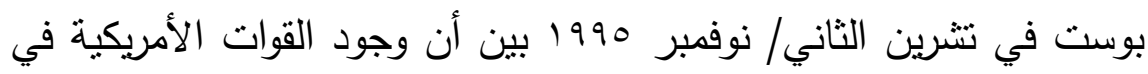

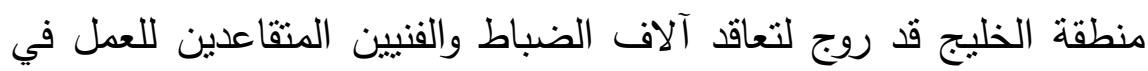

$$
\text { مجالات التدريب والصيانة(70). }
$$

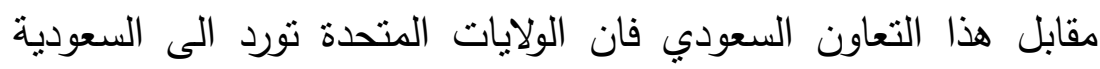

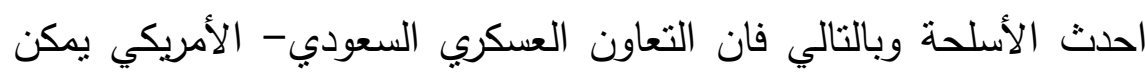

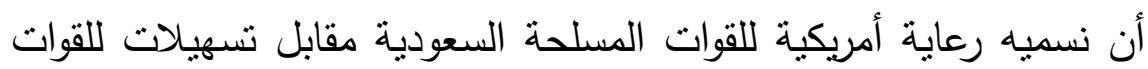




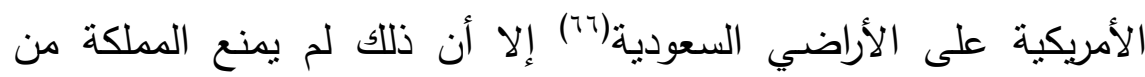

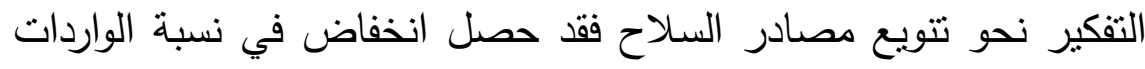

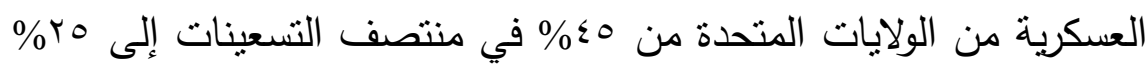

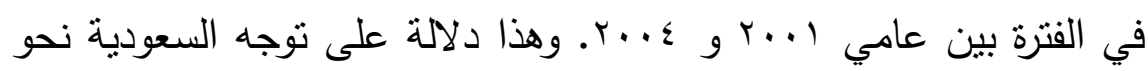

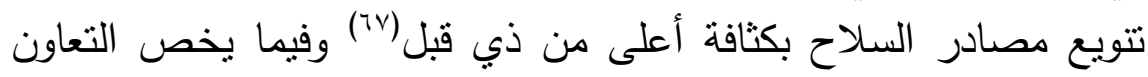

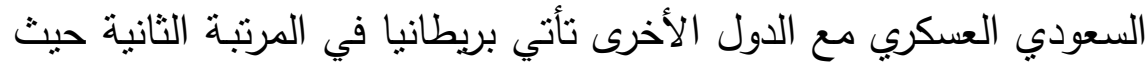

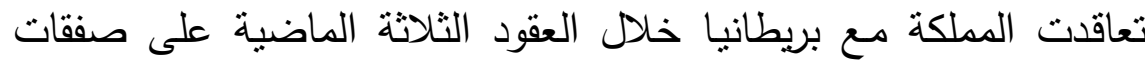

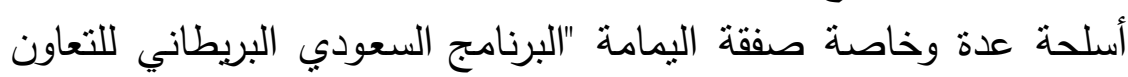

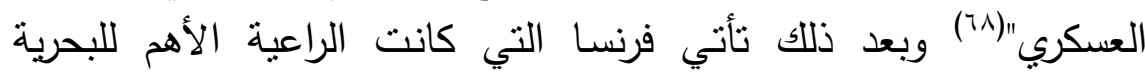

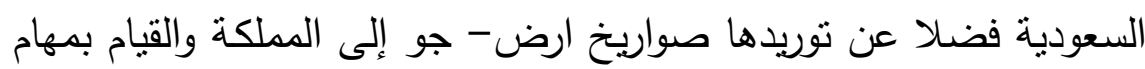
التدريب(79) وهناك تعاون سعودي نركي على مستى مستوى عالي كنلك الباكستان والمانيا(v).

ومن جانب آخر فقد فتحت المملكة أبواب معاهدها العسكرية للطلبة

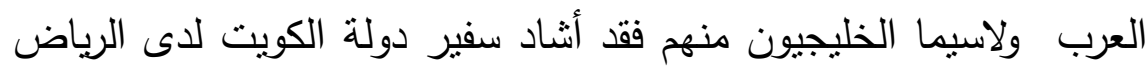

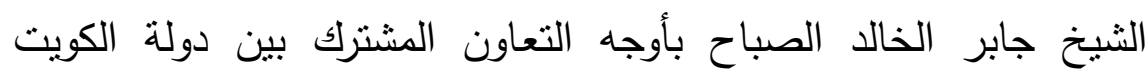

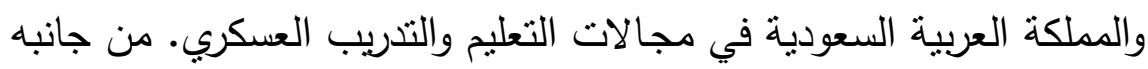

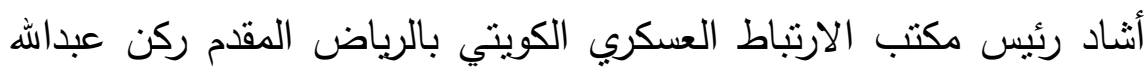

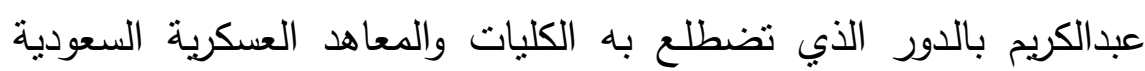

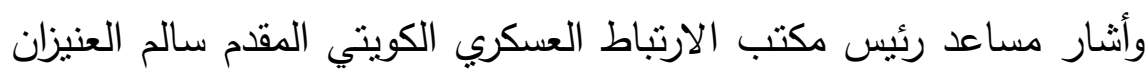
الى المستوى التعليمي المنطور في المؤسسات العسكرية السعودية ودورها

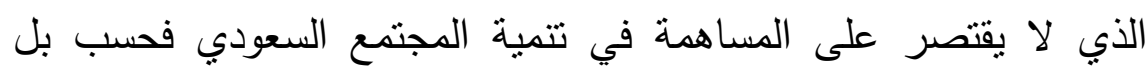

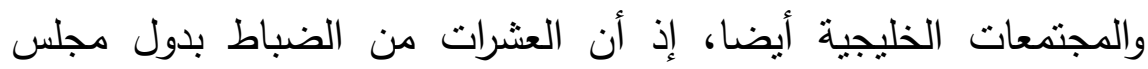

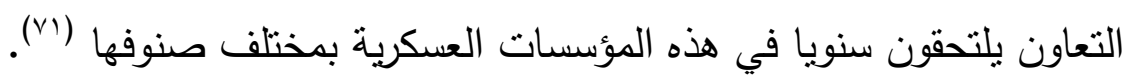




\section{هـ مستقبل القدرات العسكرية للمملكة العربية السعودية}

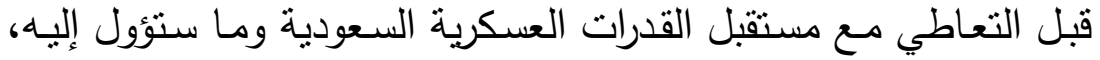

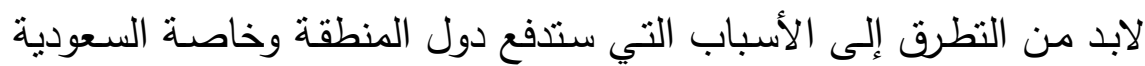

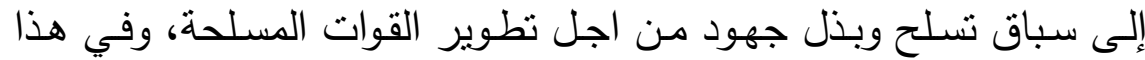

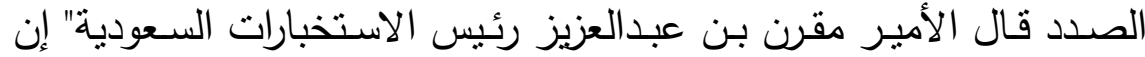

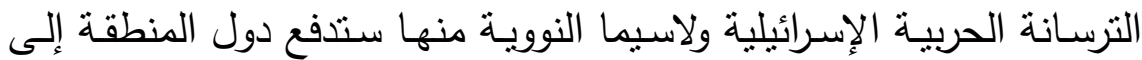

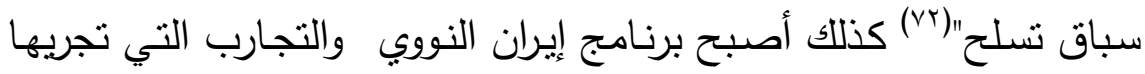
إيران على صواريخ (شهاب) و (سجيل) وغيرها من الصواريخ الإيرانية بعيدة

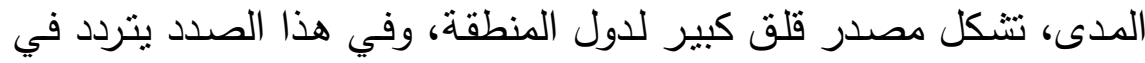

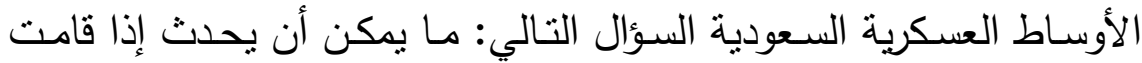

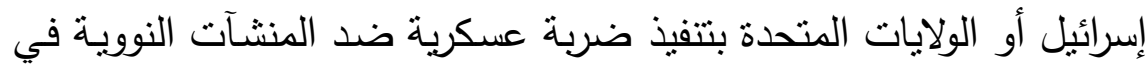

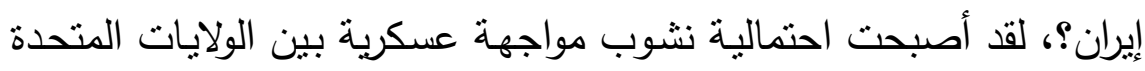

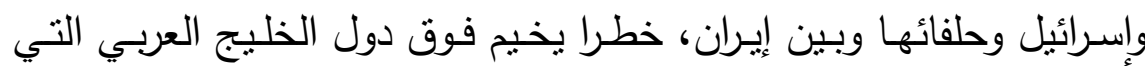

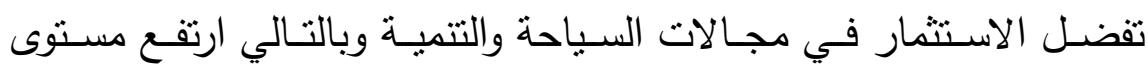

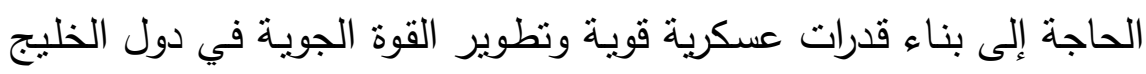

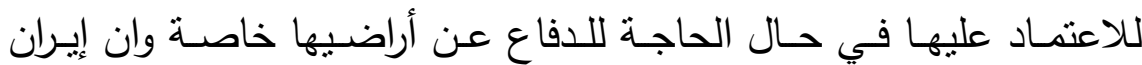

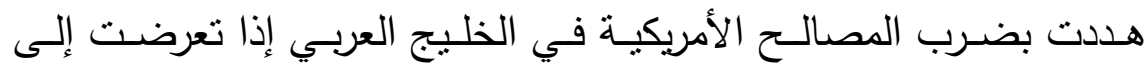
ضربة عسكرية، هذا الاعتبار جعل معرض دبي للطبران الذي يقام مرة كل

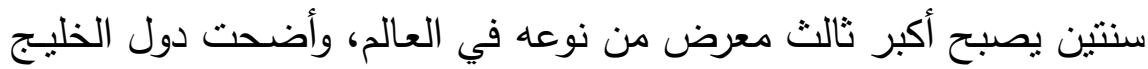

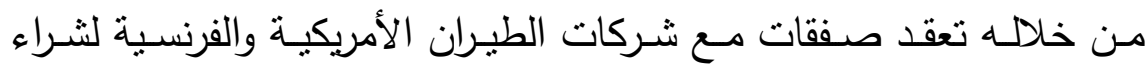
مقاتلات حديثة. كل ذلك سيسبب استنزافا لموارد دول الخليج وبشكل عام التهام

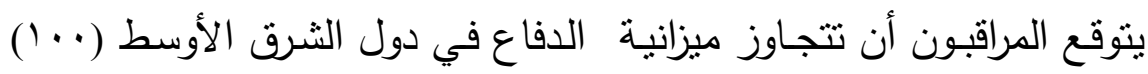

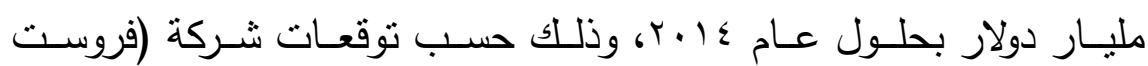

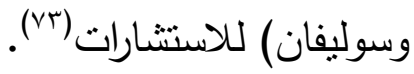


ووفق بعض التسريبات الصحفية فأن الولايات المتحدة بدأت سياسة

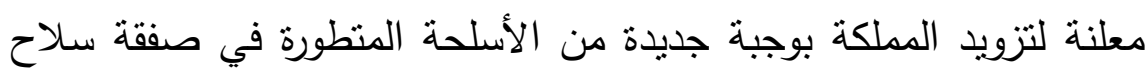

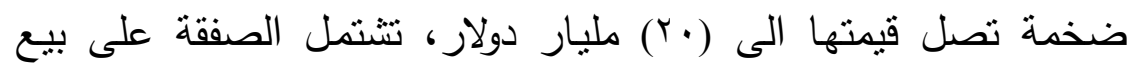

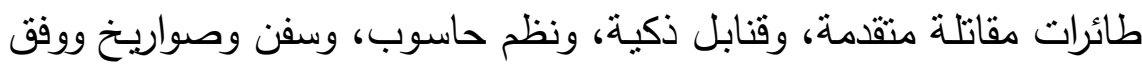

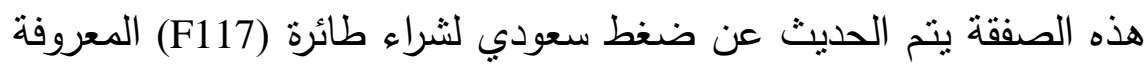

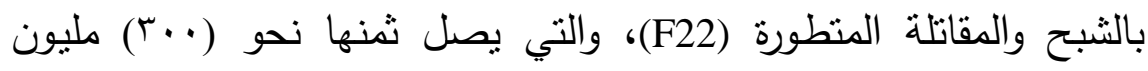

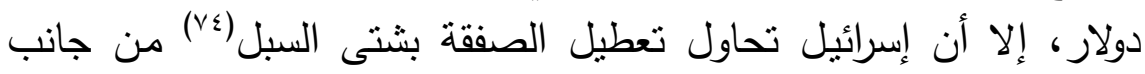

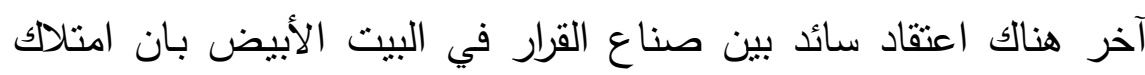

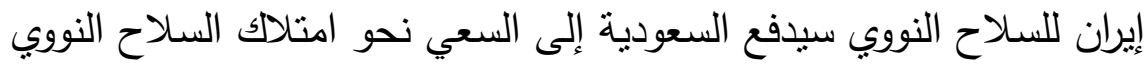

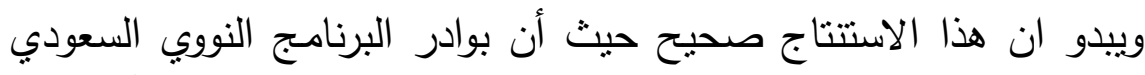

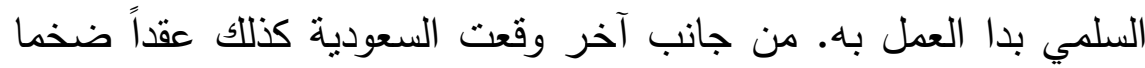
مع شركة EADS لإقامة طوق أمني شامل حول كامل حدود المملكة، يعتبر

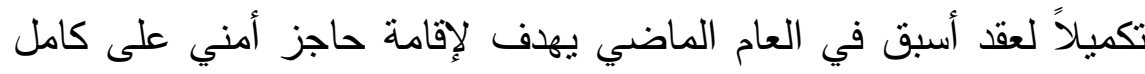

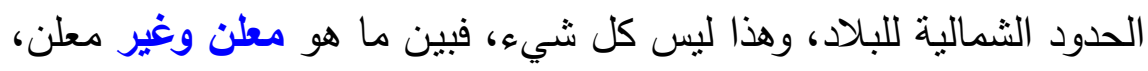

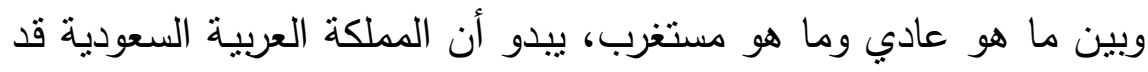

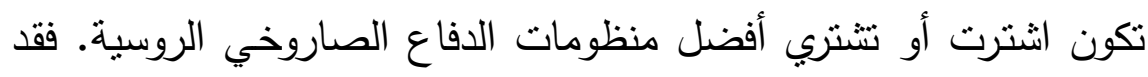

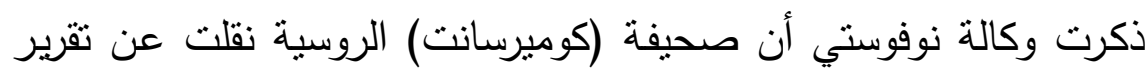

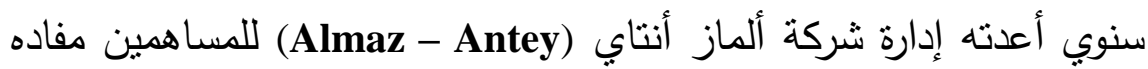

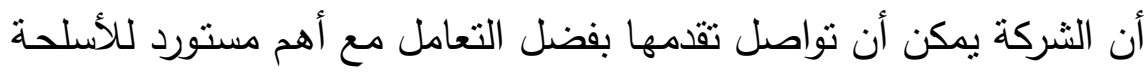

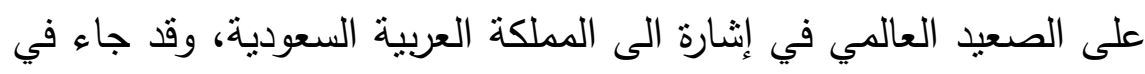

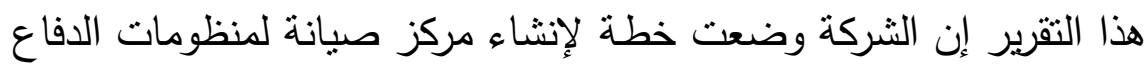

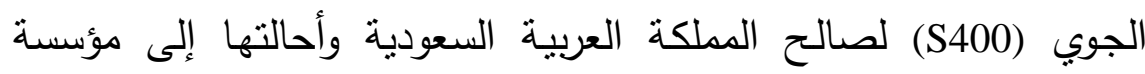

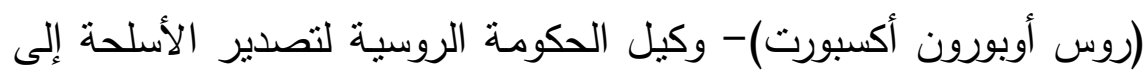

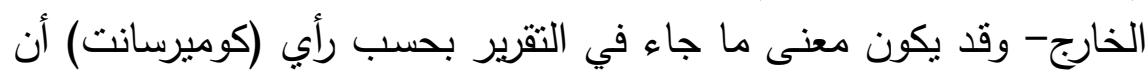
شركة الماز -انتاي كانت قد وردت مناء منظومات من طراز (S400) إلى (كميرن 
السعودية أو تستعد لتوربدها في أقرب وقت وهناك معلومات مفادها أن وزبر الخارجية السعودي سعود الفيصل بحث مع الرئيس الروسي فلاديمير بوتين

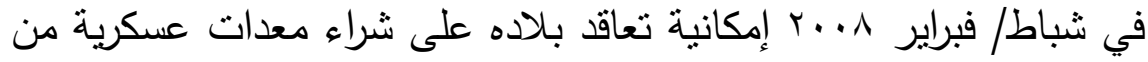
روسيا. وفقد تبين من التقرير الذي أعدته إدارة شركة الماز -انتاي أنها

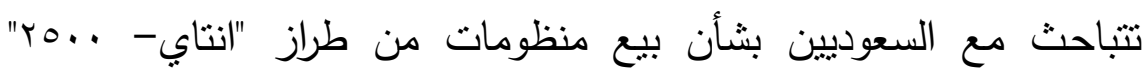

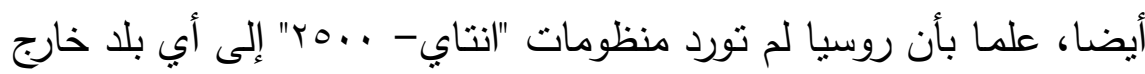
الساحة السوفيتية سابقا حتى الآن. أما الصفقة المعلنة الأحدث هي في فيام وزارة الدفاع والطيران السعودية بطلب ثنلاث طائرات صهريج ونقل متعددة الأدوار من طراز (A330 MRTT) من شركة (Airbus Military)، وستستلم السعودية الطائرة الأولى عام 2011 ومن شأن هذه الطائرات أن تعزز القدأن القدرة

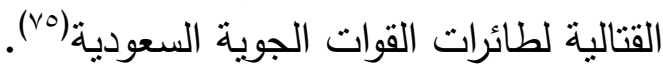

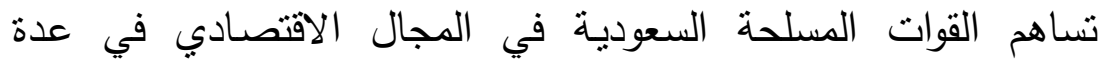

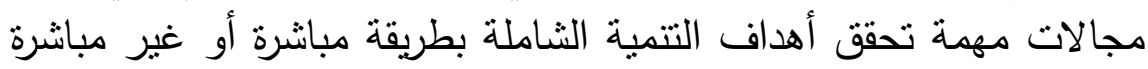

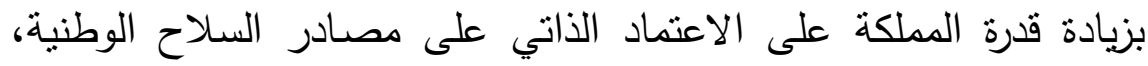
وتلبي مطلب الاستمرار في إحداث تغبير حقيقي في البنية الاقتصادية للبلاد وذلك بالتحرك المستمر نحو تتويع القاعدة الإنتاجية، ويهدف (برنامج

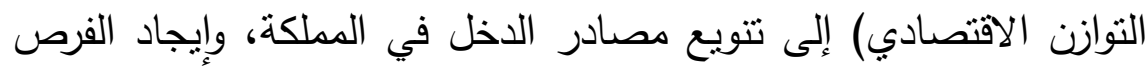

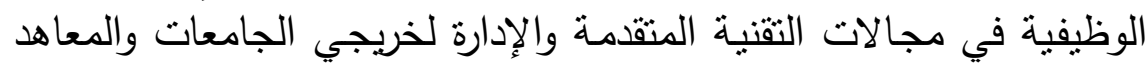
المهنية لنطوير مهاراتهم وزيادة خبراتهم، وإعطاء الفرصة للمواطنين ورجال

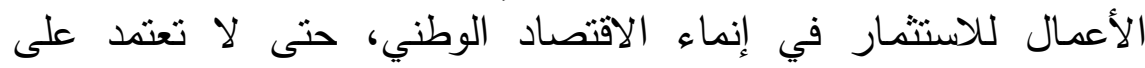

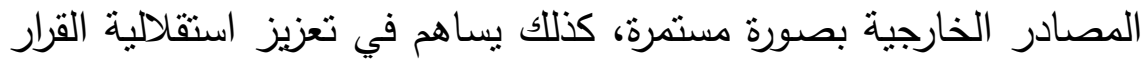
وتوفير الأمن الدفاعي للمملكة نتيجة لإقامة الصناعات العسكرية الوطنية

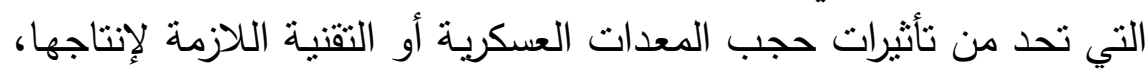
كما أن توفير هذه الصناعات وخدماتها سيؤدي إلى ضدئ ضدان جاهزية القطعات العسكرية إضافة إلى هذا، فإنه سيوفر مرونة للقوات المسلحة عنداتهات 


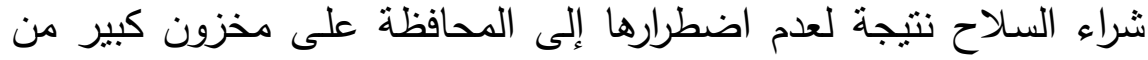

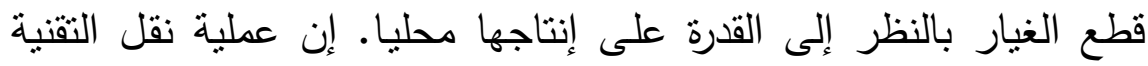

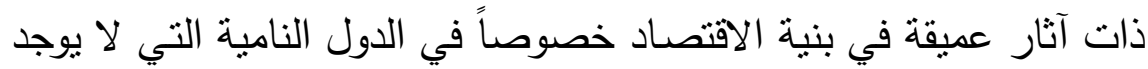

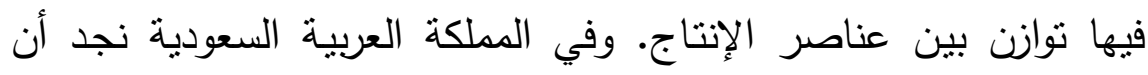

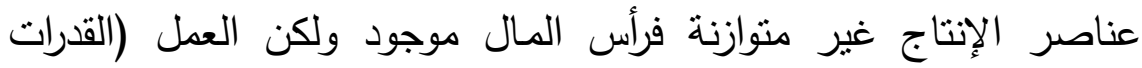

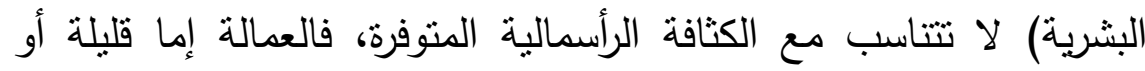

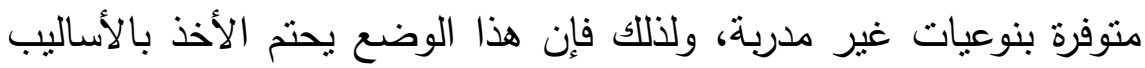

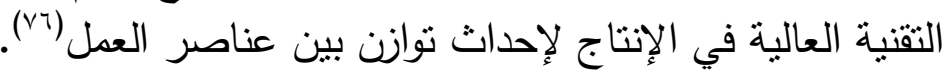

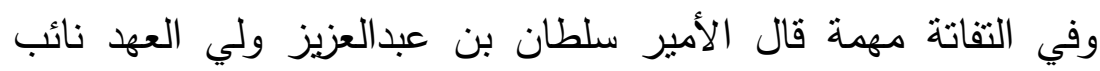

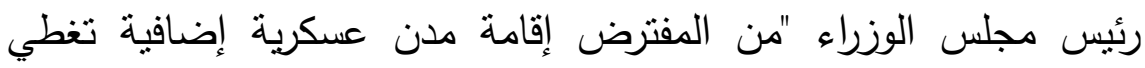

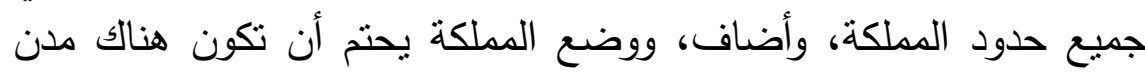

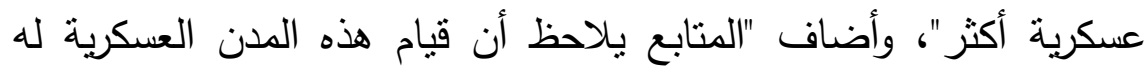

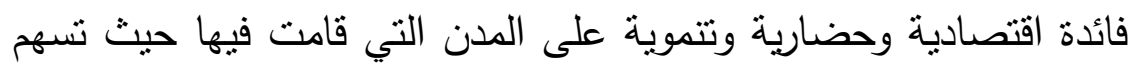

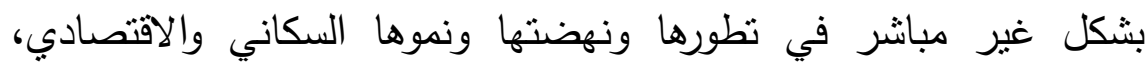
فكيف كانت تبوك وخميس مشيط وحفر الباطن والخرج والمنطقة الشرقية ونائ

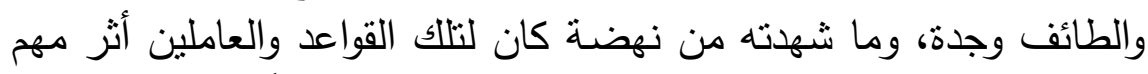

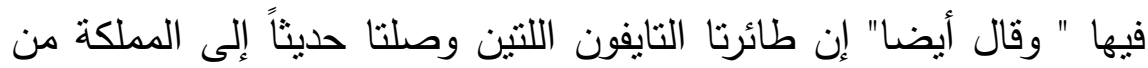

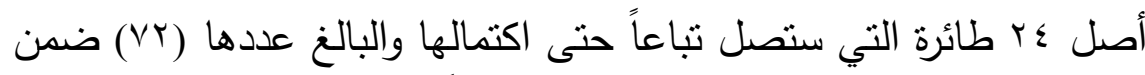

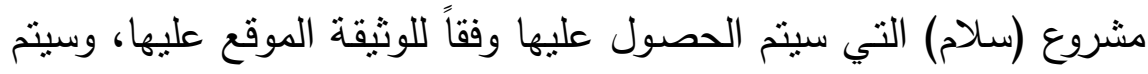

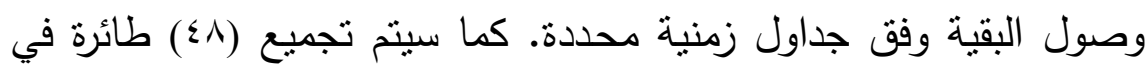

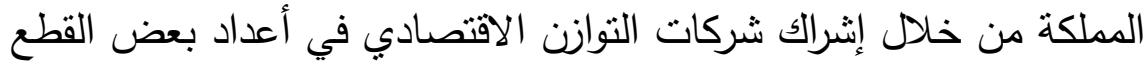

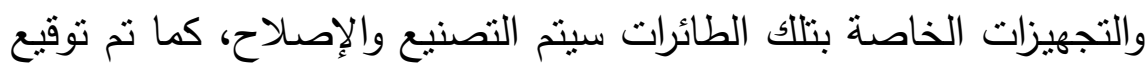

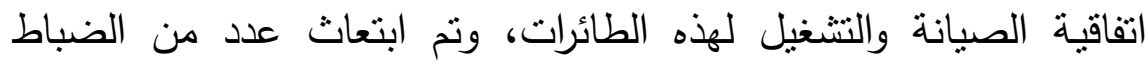

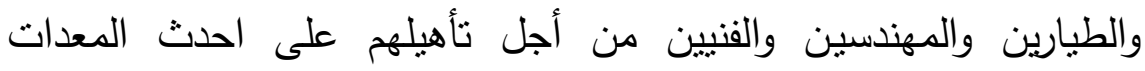

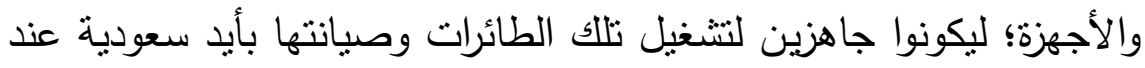

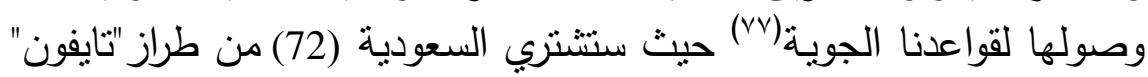


الأوربي الصنع مما سيعزز القدرات القتالية لسلاح الجو السعودي إذ ستزود

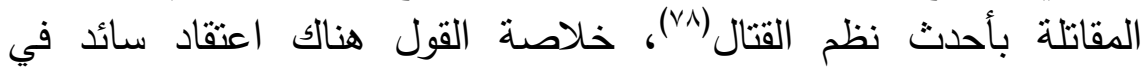
الأوساط الأمنية داخل وخارج المملكة إنها ستبقى تعتمد على الولايات المتحدة كظامن لأمن المملكة من التهديدات الخارجية(V9). خاتمة واستتناجات يعد العام 19 ا الانطلاقة الأولية للقوات المسلحة السعودية بعد فترات من الاعتماد على المقاتلين وفق مبدأ النفير الذي كان الملك عبدالعزيز بن الند سـود يتبعـه منـذ سيطرته على الريـاض، واسـتعادتها مـن آل الرشـيد عـام

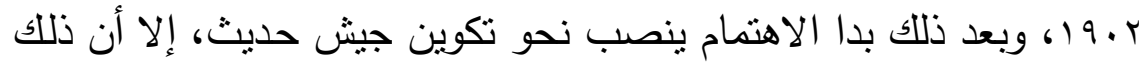

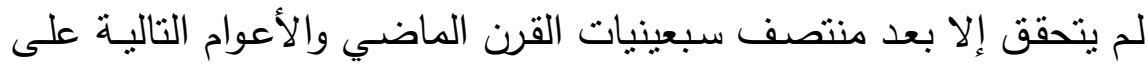

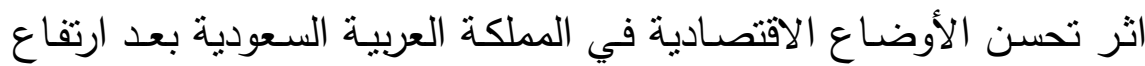

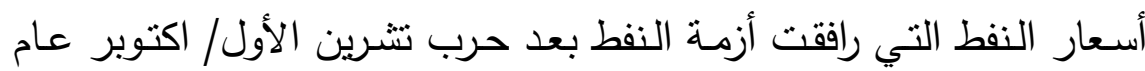

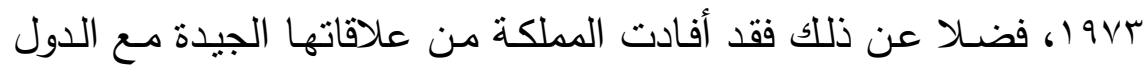
الغربية ولاسيما الولايات المتحدة المتواجدة عسكريا على الأراضي السعودية،

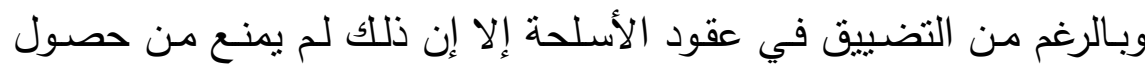

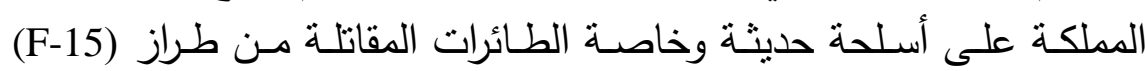
وطائرة (التورنادو) البربطانية الصنع. ومن خلال هذا البحث تم التوصل إلى ماتى عدد من الاستنتاجات أهمها: ا- يمكن أن نعد الجيش السعودي واحدا مـن أهم الجيوش العربيـة، لكنه الهـه

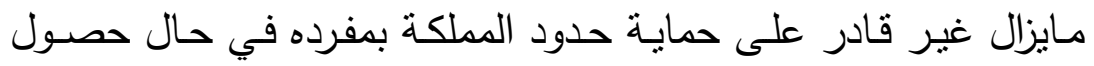
اعتداء من جيش آخر، فعدد أفراد الجيش السعودي لا يتناسب مـع حجم

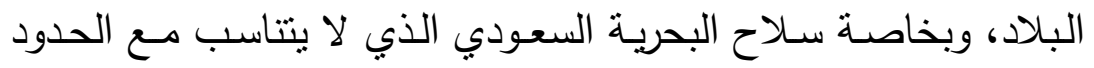
البحرية الثاسعة للمملكة. r- هنالك اهتمام واضتح من صناع القرار السياسي في المملكة بالقوة الجوية مما جعل الصنوف الأخرى للجيش اقل كفاءة. 
دراسات إقليمية 7 (·) (†)

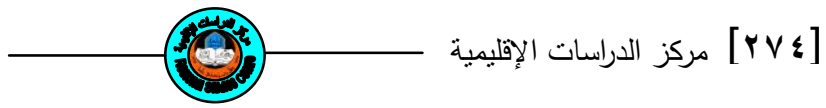

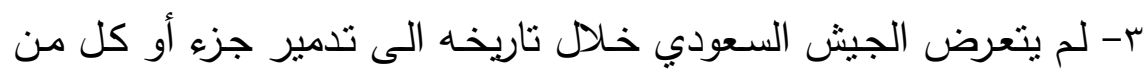

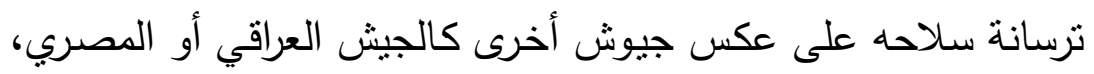

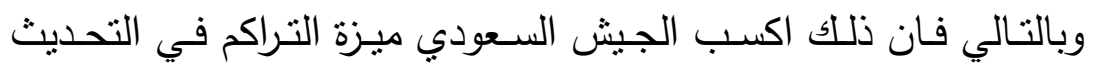

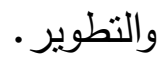

ع- وفرت الإمكانات المالية الضخمة فرصة للمملكة لثراء احدث الأسلحة

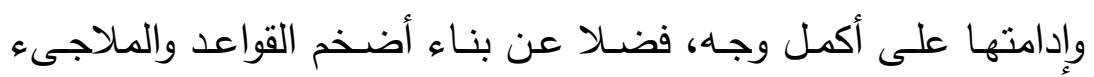

التي تعجز العديد من الدول على تحمل نفقاتها.

\title{
Military Abfliies of Saudi Arabia
}

\section{By:Mithak Khynallah Jalud}

\begin{abstract}
Saudi Arabia was able to Surpass important obstacles and got use of its good relations with the advanced start as to got advanced weapons, in addition to start the military industry during the last ten years. The year 1926 is considered the first beginning of armed forces in Saudi Arabia after the periods of depending upon combatants of horn principle used by king Abdul-Aziz bin Saud since he was controlling Al-Rayadh getting it back from Al-Rasheed in 1902. After that, interest was directed to wards building a modern army but this did not complete till mid of 1970s and the following years due to improving the economic in Saudi Arabia. The kingdom benefited from its good relations with the western states especially united states with its troops on the Saudi lands. In spite of the shortage in arms contracts, but this did not prevent the kingdom from getting modern weapons especially F.15 planes and the British plane(Tornado).
\end{abstract}




\section{الـهوامش والمصادر}

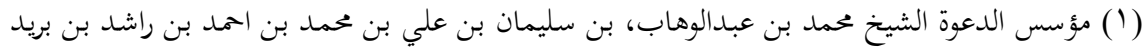

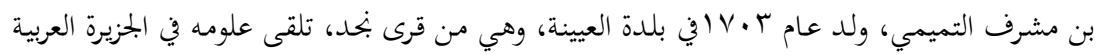

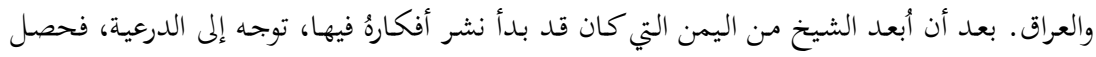

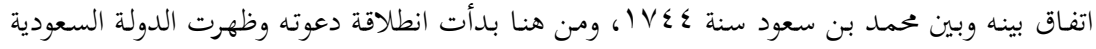

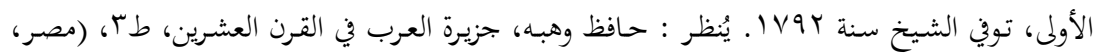
( )

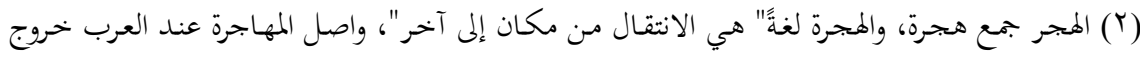

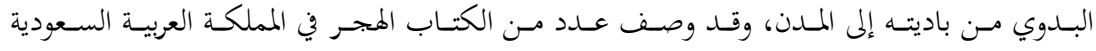

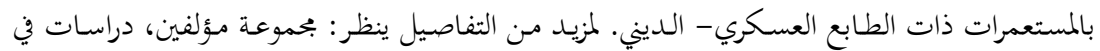

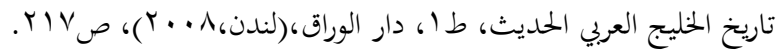

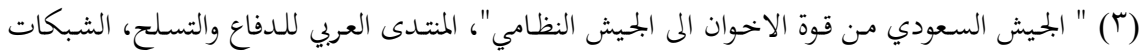
defense-arab.com/vb/showthread.php?t=20722 المتصلة (الانترنت): (ع) القوات البرية الملكية السعودية، ويكيبيديا الموسوعة الحرة، الشبكات المتصلة(الانترنت): http://ar.wikipedia.org/wiki

(0) القوات الجوية الملكية السعودية، ويكيبيديا الموسوعة الحرة، المصدر السابق

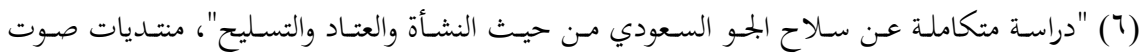
فلسطين، الشبكات المتصلة (الانترنت): (V) وزارة الدفاع والطيران، القوات البحرية الملكية السعودية، الموقع الرسمي على الشبكات المتصلة (الانترنت): www.moda.gov.sa/ (^) القوات البحرية الملكية السعودية، ويكيبيديا الموسوعة الحرة، المصدر السابق.

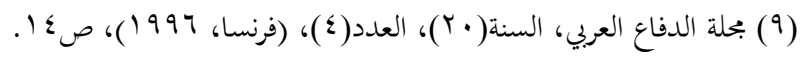

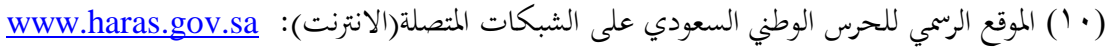

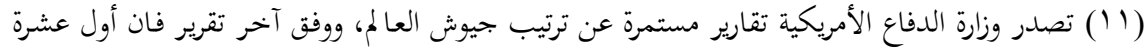

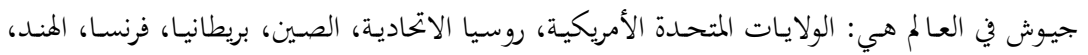




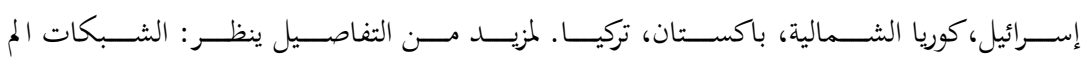
www.saudistudents.org/vb/showthread.php?t=81436

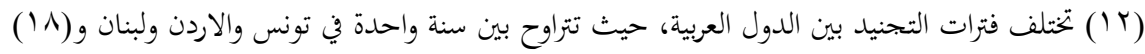

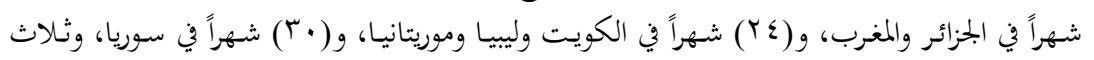

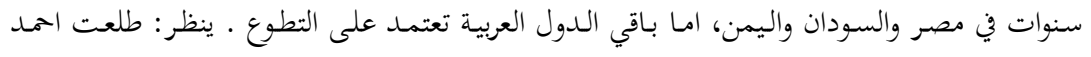

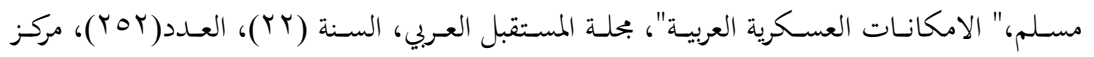

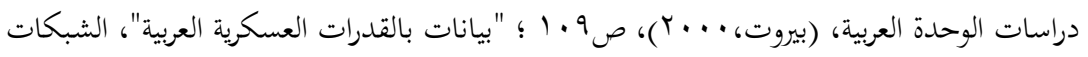

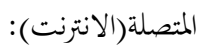

www.alsakher.com/vb2/showthread.php?t=131047

(rT1) " الموضوع الجمامع للقوات المسلحة الملكية السعودية"، ساحات الطيران العربي، الشبكات المتصلة

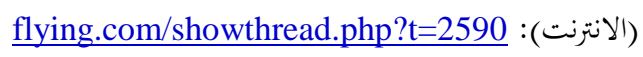

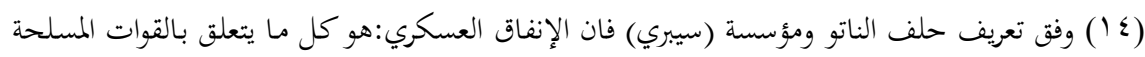

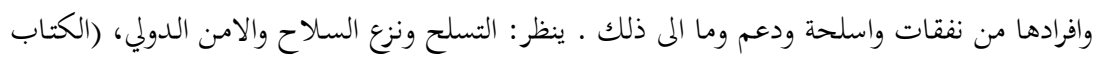

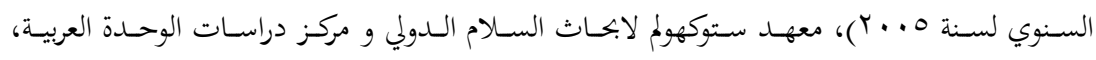

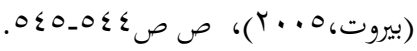

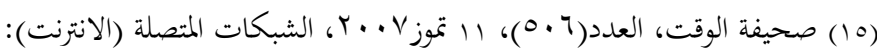
www.alwaqt.com/art.php?aid=64258

$$
\text { (17) الجدول من عمل الباحث بالاعتماد على: }
$$

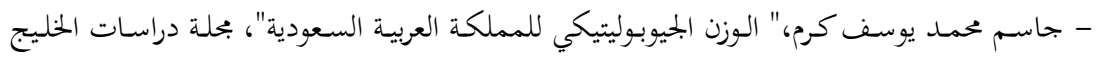

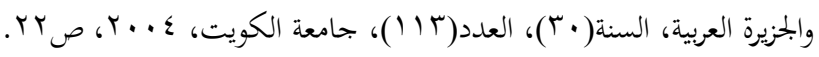

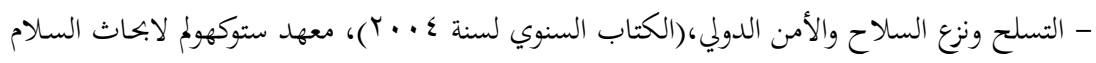

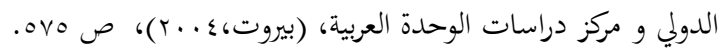

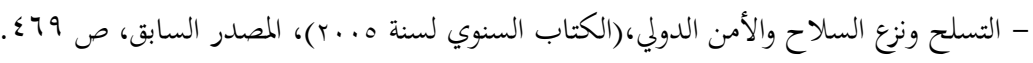

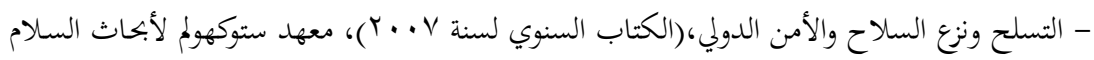

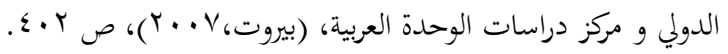

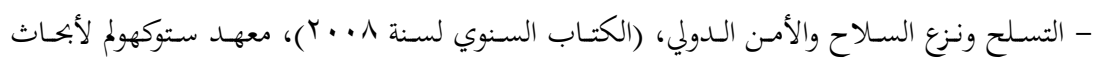

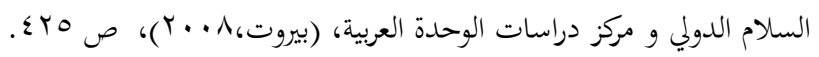

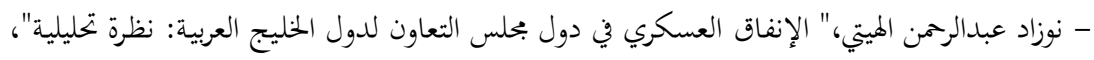

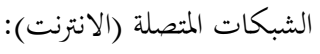

corp.gulfinthemedia.com/files/gim editorial/2128.pdf?PHPSESSID 


$$
\text { - الموضوع الجامع للقوات المسلحة، المصدر السابق. }
$$

- WUYI OMITOOGUN," Appendix 10E. Military expenditure in the Middle

East after the Iraq war": www.IISS.com

$$
\text { (IN) (IV) الموضوع الجامع للقوات المسلحة، المصدر السابق. }
$$

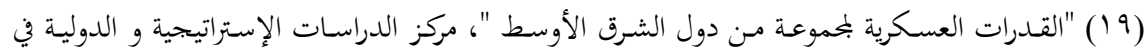
www.taqrir.org/showarticle.cfm?id=428

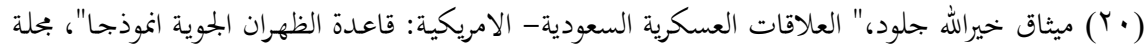

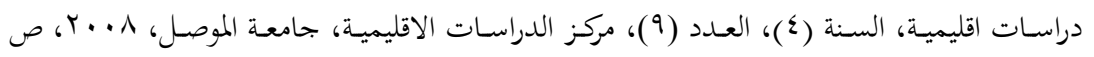

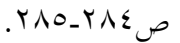

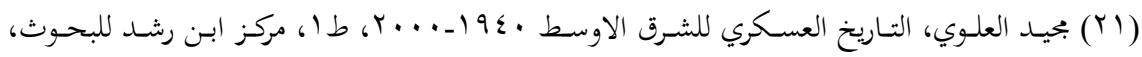

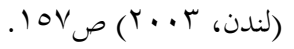

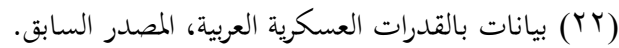

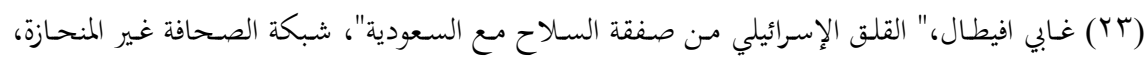
www.voltairenet.org/article150503.html الشبكات المتصلة (الانترنت):

$$
\text { (Y (Y) دراسة متكاملة عن سلاح الجو السعودي من حيث النشأة، المصدر السابق. }
$$

(25) Christopher M. Blanchard," Saudi Arabia: Background and Relations", U.S.,

Congressional Research Service, Middle Eastern Affairs, 9July 2009, P.16.

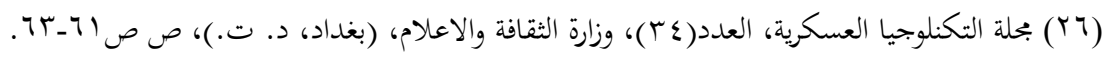

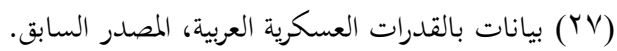
(YA) (سلاح الجو السعودي"، قناة الجزيرة الفضائية، الشبكات المتصلة (الانترنت): www.aljaazera.com

$$
\text { (†q) موقع ساحات الطيران العربي، الشبكات المتصلة (الانترنت): }
$$

flying.com/showthread.php?t=2590ء

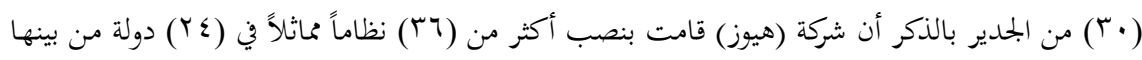

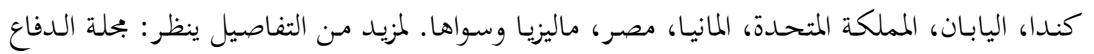

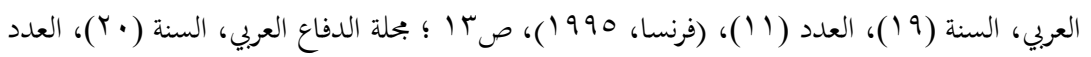

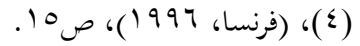

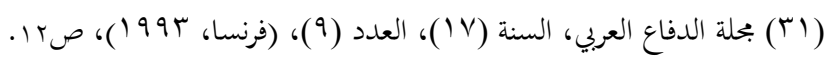




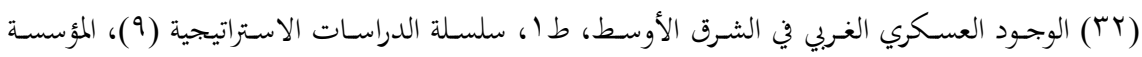

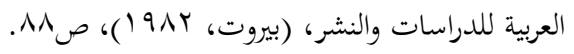

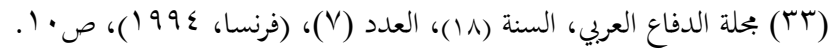

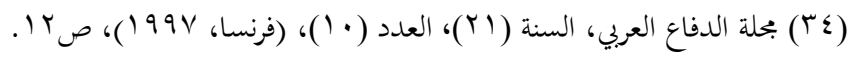

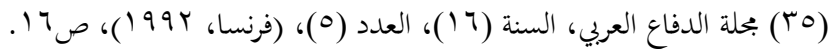

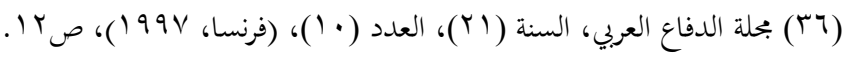

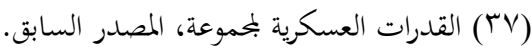

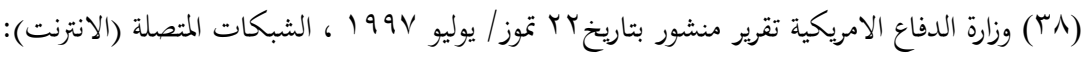
www.defense.gov

$$
\begin{aligned}
& \text { (\%q) القدرات العسكرية بلمموعة، المصدر السابق. }
\end{aligned}
$$

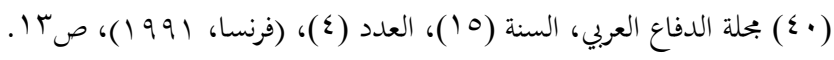

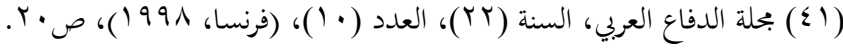

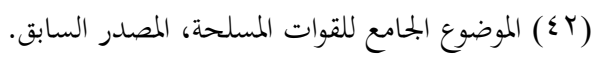

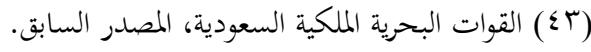

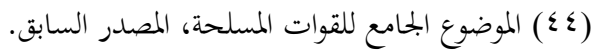

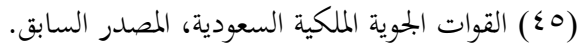

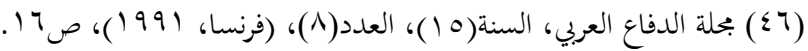

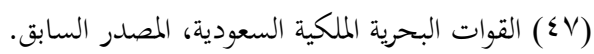

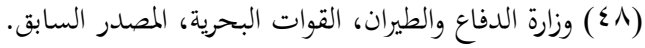

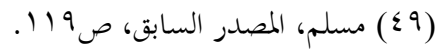

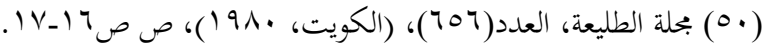

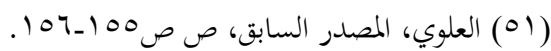

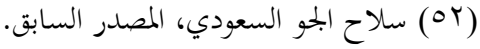

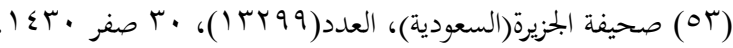

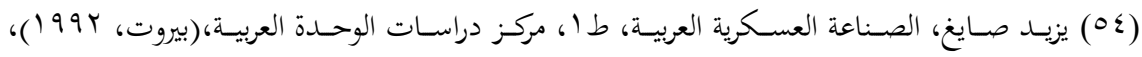

$$
\begin{aligned}
& \text { ص PVT }
\end{aligned}
$$

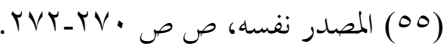

$$
\begin{aligned}
& \text { (07) "صناعة السلاح والتقنيات الحربية في السعودية"، موقع ساحات الطيران، المصدر السابق. }
\end{aligned}
$$

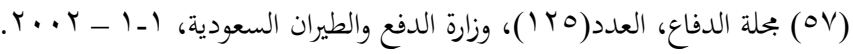

$$
\begin{aligned}
& \text { ) (ON) صناعة السلاح والتقنيات، المصدر السابق. }
\end{aligned}
$$




$$
\begin{aligned}
& \text { (109) الموضوع الجامع للقوات المسلحة ، المصدر السابق. }
\end{aligned}
$$

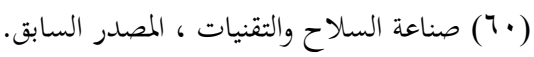

$$
\begin{aligned}
& \text { (7) (7) الموضوع الجامع للقوات المسلحة، المصدر السابق. }
\end{aligned}
$$

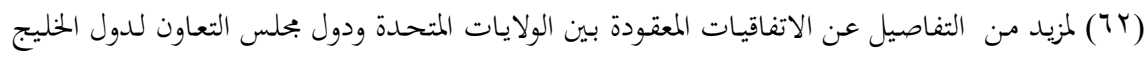

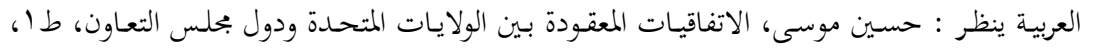

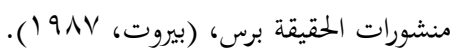

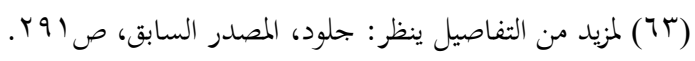

( (ج) ابراهيم ناجي علوش، " الوجود العسكري الامريكي في المنطقة"، الشبكات المتصلة (الانترنت): http://www.freearabvoice.org/arabi/kuttab/alwjoodAl3askareeHona

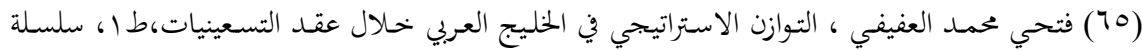

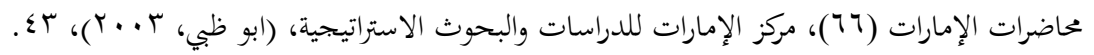

$$
\text { (דآ) موقع انباء الاخباري، الشبكات المتصلة (الانترنت): }
$$

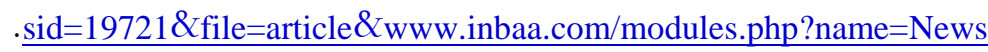

$$
\text { (ال) موقع اخبار الغد، الشبكات المتصلة(الانترنت): }
$$

.www.alghadnews.com/alghad/show.php?id=789

$$
\text { (7^) موقع قناة العربية الفضائية، الشبكات المتصلة (الانترنت): }
$$

.www.alarabiya.net/articles/2009/07/19/79223.html

(69) Perspectives de contrats colossaux avec l'Arabie Saoudite, TTU:

www.ttu.fr/francais/Articles/programmesaoudie.html

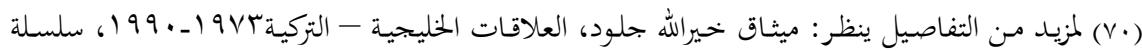

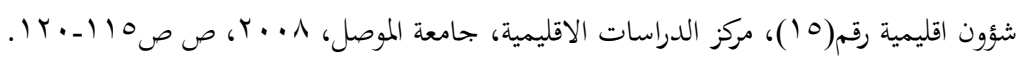

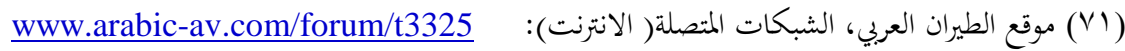

(72) Thomas W. Lippman, "Nuclear Weapons and Saudi Strategy", The Middle

East Institute Policy Brief, No. (5), January2008,P.6.

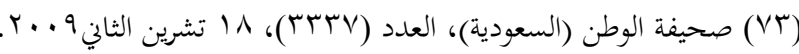

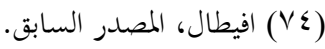

$$
\begin{aligned}
& \text { (V0) المنتدى العربي للدفع والتسلح، الشبكات المتصلة (الانترنت): }
\end{aligned}
$$

defense-arab.com/vb/showthread.php?t=20722

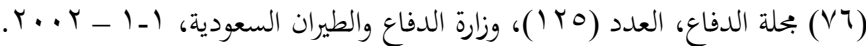

$$
\begin{aligned}
& \text { (VV) موقع قناة العربية، المصدر السابق. (VV) }
\end{aligned}
$$


دراسات إقليمية 7 (r)

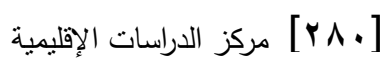

(79) Blanchard, Op. Cit., P.16.

المنتدى العربي للدفع والتسلح، المصدر السابق. (V^) 